\title{
Comparative Transcriptome Analysis Uncovers Genes and Pathways Relating to Downy Mildew Resistance in Isabgol (Plantago ovata Forsk.)
}

Manivel Ponnuchamy

Directorate of Medicinal and Aromatic Plants Research

Sandip Patel

Directorate of Medicinal and Aromatic Plants Research

Jincy Mathew

Directorate of Medicinal and Aromatic Plants Research

Jitendra Kumar

Directorate of Medicinal and Aromatic Plants Research

Nagaraja Reddy Rama Reddy ( $\sim$ gpbreddy@gmail.com )

Directorate of Medicinal and Aromatic Plants Research

Research article

Keywords: Isabgol, Downy mildew, Transcriptome analysis, Next generation Sequencing, Resistance genes

Posted Date: March 9th, 2020

DOI: https://doi.org/10.21203/rs.3.rs-16428/v1

License: (c) (i) This work is licensed under a Creative Commons Attribution 4.0 International License. Read Full License 


\section{Abstract}

\section{Background}

Isabgol (Plantago ovata Forsk.) downy mildew (DM), caused by obligate oomycete pathogen Peronospora plantaginis Underwood., is the single most damaging disease of Isabgol. However, reports on the genes and pathways involved in mediating resistance are still unknown.

\section{Results}

In the present study, transcriptomic analysis was carried out by next generation sequencing of DM infected and uninfected leaves of resistant and susceptible genotypes to understand the genetic mechanisms underlie the host-plant resistance. A total of 33.47 million reads were generated and de novo assembled and annotated. The assembly using Trinity yielded 38803, 40175, 45451 and 39533 non-redundant transcript contigs, respectively in susceptible infected, Susceptible uninfected, Resistant infected and resistant uninfected samples. More than $90 \%$ of coding DNA sequence (CDS) predicted were annotated using BLAST search. Isabgol transcriptome showed the highest similarity to Sesamum indicum (41-59\%) followed by Erythranthe guttata (10-13\%). Putative CDS encoding Pathogen associated Molecular Pattern (PAMP)-triggered immunity (PTI), Effector-Triggered Immunity (ETI), Cell wall degrading enzymes, Phytohormone signalling and Phenylpropanoid biosynthesis pathways involved in host-pathogen interaction were identified in addition to the identification of several candidate resistance (R) genes enriched in response to DM infection. We identified significantly differentially expressed genes (DEGs) genes; 6928 DEGs in resistant uninfected (RU) vs resistant infected (RI) of DPO-185 (resistant) genotype and 8779 susceptible uninfected (SU) vs susceptible infected (SI) of DPO-14 (susceptible) genotype. Expression of 11 genes involved in plant defense quantified accordingly using RT-qPCR.

\section{Conclusions}

This study for the first time provides the glimpse of transcriptional responses to the DM resistance in Isabgol. The genes and pathways will be helpful in further investigating the molecular mechanisms associated with DM disease resistance in Isabgol and to develop control mechanisms accordingly.

\section{Background}

Isabgol (Plantago ovata Forsk.) belongs to Plantaginaceae family, is an important medicinal plant commercially grown in India. The external seed coat, 'psyllium husk' of commerce is an excellent dietary fibre and is commonly known as "Isabgol" in Hindi and "Blonde Psyllium" in English. The isabgol husk (epicarp of seed) has medicinal properties and is used against constipation and irritation of digestive tract. Psyllium husk (25-30\% of seed) has the property of absorbing and retaining water and hence, it works as an anti-diarrheal drug [1]. The husk is also used in calico printing, dyeing, agar-agar media preparation, gum and jelly making, as binder in tablets, as thickener and a fixative in ice-cream, confectionary and in cosmetics industries [1]. It has been used as a deflocculant in paper and textile manufacturing, as an emulsifying agent, as binder or lubricant in meat products, and as a replacement of fat in low-calorie foods [1]. India is the sole exporter of isabgol husk and seed to the world market [2]. More recently, it has been included in the diversified food products to supplement fibre intake in different countries including USA and European countries [3]. Isabgol is largely cultivated in Rajasthan, Gujarat and Madhya Pradesh in India. Isabgol has a narrow genetic base on account of small, mostly heterochromatic chromosomes with low chiasmata frequency and recombination index [3]. It is a diploid $(2 \mathrm{n}=2 \mathrm{x}=8)$ plant with a genome size of about $621 \mathrm{Mb}$ [3]. The haploid genome is about 1.6 times larger than that of the rice genome.

Plant defense response is a complex process, involving multiple signalling pathways and their cross talks [4-5]. Immune system perceive the pathogen elicitors which allow plant to switch from normal growth and development to defense mode through various surveillance systems [6]. The activation of pattern recognition receptors (PRRs) by pathogen-associated molecular patterns (PAMPs) at the surface of the plant elicits a defense response known as PAMPtriggered immunity (PTI) [7]. PTI normally prevents non-adapted microbes from infecting and is therefore an important barrier against diseases [7]. For surviving, pathogens evolved effector proteins to suppress PTI, accordingly plants also have evolved Resistance (R) proteins to recognize these effectors, eventually resulting in the next level of plant defense called effector-triggered immunity (ETI) [8-9]. R-proteins can directly sense pathogen effectors, or they can detect pathogens through other cofactors, which are direct host targets of pathogens [9]. Besides, the other signalling pathways like phytohormone signalling, ubiquitin mediated proteolysis and polyprionid biosynthesis involved in the defence response to the pathogens in plants, too [10]. Defense responses include strengthening the cell walls [11], the synthesis of pathogenesis related (PR) proteins and antimicrobial compounds such as phytoalexins [12], and the hypersensitive response (HR), in which cells undergo programmed cell death in the infected region to block further spreading of the pathogen [13].

The oomycete pathogen Peronospora plantaginis (PP) causes Downy mildew (DM) disease of Isabgol is a typical obligate biotroph [14-15]. The pathogen releases motile zoospores on the host plant and enters leaves through stomata [16]. Like other DM pathogens, the colonization of PP fungi is achieved by germinating zoospores, intercellar mycelia growth in the host cells and formation of haustoria. DM of isabgol produces symptoms in leaves as well as floral parts [17]. Disease affected leaves show characteristic ash-coloured downy growth, and as the disease progresses, leaves turn yellowish due to loss of chlorophyll, ultimately reducing effective photosynthetic area [14]. DM outbreak coincides with flowering time and spreads considerably during anthesis and grain filling phases [18]. Floral infection includes systemic infection resulted in long spikes bearing weak and sterile florets, which later turned black due to saprophytic growth [15]. DM disease adversely affects seed yield (73.45\% loss) and quality of Isabgol [15].

Controlling the disease through chemical sprays not economical to the farmers besides being environmentally unsustainable. Therefore, development DM resistant varieties is one of the objectives of Isabgol breeding, especially in the warm and humid Isabgol-growing regions where the DM disease occurs regularly. It has also been recognized as one of the most economical, environmentally safe and effective strategies for disease control [19]. The available varieties of Isabgol are susceptible to DM, with poor to moderate yielders. Development of DM resistant varieties becomes a challenge for Isabgol breeders. Characterization of the mechanism underlying DM resistance and the breeding new varieties with resistance and good agronomic traits have been very 
difficult because resistance to DM is a complex trait and controlled by polygenes [20-21]. Furthermore, current understanding of DM resistance mechanism in Isabgol at the enzyme, gene and regulatory levels is incomplete. Recently, genome-wide studies of model plant species have resulted in an increase in our knowledge of, and capacity to understand, basic biological processes. More specifically, transcriptome analysis has great promise in identification of various genes involved in plant resistance. Transcriptome analysis gives the gene index of an organism quickly, is used to identify the genes involved in specific resistance pathways [22]. Therefore, transcriptome analysis has been successfully used to investigate the specific resistance genes and pathways against DM of grapes [23-29] and Arabidopsis [30-31], suggesting that plant defense in response to DM infection is regulated through a complex network involving a large number of genes. Many candidate genes such as RPP, PMR4, RabhA4C, RPW8.1, RPW8.2, PRs, NPRs and WRKY shown to play an important role in resistance and response to DM in Arabidopsis [32-33].

With respect to Isabgol, only a few studies are on the transcriptomic resources:[34] characterized the mucilage biosynthesis pathways in $P$. ovata using 46,955 unique transcripts, [35] characterized genes involved in xylan biosynthesis using 1,099158 ESTs and [36] generated $250 \mathrm{Mb}$ whole genome sequence to develop simple sequence repeat (SSR) markers for breeding applications. [37-38] sequenced 5,900 ESTs and 3,247 independent mRNAs from the leaf vascular tissue of Plantago major, a relative of Plantago ovata and no complete transcriptome analysis is available in the public domain to understand DM resistance in Isabgol.

Thus, the major objective of the present study is to uncover the genes and pathway relating to host-plant resistance against fungal pathogen $P$. plantaginis responsible for DM disease of Isabgol by using RNA sequencing technologies. Gene expression profiles were compared between a DM resistant (DPO-185) and DM susceptible (DPO-14) genotypes of Isabgol. Thus, our study will lead to better understanding of the molecular mechanisms regulating DM resistance in Isabgol.

\section{Results}

\section{Resistance and susceptible reaction of genotypes}

Two Isabgol genotypes DPO-14 and DPO-185 were evaluvated for DM resistance during 2014-2017 by artificial inoculation of PP spores under field condition. The genotype DPO-14 recorded mean score of 4.8 with the score ranging from 4.5 to 5.0 across seasons (Fig. 1). While the genotype DPO-185 recorded mean score of 1.1 with score ranging from 1.0 to 1.5 across seasons indicating the resistance or susceptibility of genotypes to the incidence of DM disease. DPO-14 has most prominent ash-coloured downy growth on the leaves, leaves turn yellowish at the time of flowering, ultimately leading to plant mortality as the disease progresses. A sporadic presence of ash-coloured downy growth on the leaves were found in DPO-185 at the time of flowering.

\section{Illumina sequencing and annotation}

Four cDNA libraries from susceptible infected (SI) and susceptible uninfected (SU) leaves of DPO-14 (DM susceptible) and resistant infected (RI) and resistant uninfected (RU) leaves of DPO-185 (DM resistant) genotypes were sequenced using Illumina Hi-Seq platform. Sequencing data included 94,02386 raw reads containing 2735985710 nucleotide bases for SI, 89,76119 raw reads containing 2628972037 nucleotide bases for SU, 108,14932 raw reads containing 3107632713 nucleotide bases for RI and 42,82684 raw reads containing 1267265127 nucleotide bases for RU (Table 1). The raw paired-end sequencing data in FASTQ format was deposited in the National Center for Biotechnology Information (NCBI) BioProject database (as Short Read Archive) under accession number PRJNA382334. De novo assembly yielded 38803, 40175, 45451 and 39533 non-redundant transcript contigs, respectively in SI, SU, RI and RU after filtering out those shorter than 200 bases. The Transcriptome Shotgun Assembly (TSA) project was deposited at DDBJ/EMBL/GenBank under the accession GFNS00000000. The version described in this paper is the first version, GFNS01000000. The N50 values of the assembly was $1205,697,377$ and $1158 \mathrm{bp}$ respectively to SI, SU, RI and RU libraries, indicating fairly good transcriptome assembly. The total transcript length was 38098478 (38.09 Mb) bases, with average transcript length of 982 bases in SI, 23323465 bases (23.3 Mb), with average transcript length of 581 bases in SU,16682558 bases (16.6 Mb), with average transcript length of 367 bases in RI and 34131338 bases (34.13 Mb), with average transcript length of 863 bases in RU. A total of 26569, 18605 , 28588 and 22599 CDS, respectively in SI, SU, RI and RU were predicted. The maximum CDS length was found to be 15279 bp, whereas minimum CDS length was $147 \mathrm{bp}$ across libraries (Table 1).

Table 1. Raw reads, assembly and Coding DNA Sequence (CDS) statistics of leaf transcriptome of Isabgol (Plantago ovata Forsk.) 


\begin{tabular}{|lllll|}
\hline Read statistics & SI & SU & RI & RU \\
\hline Total reads & 9402386 & 8976119 & 10814932 & 4282684 \\
\hline Total number of nucleotides (bp) & 2735985710 & 2628972037 & 3107632713 & 1267265127 \\
\hline Assembly statistics & & & & \\
\hline Number of transcript contigs & 38803 & 40175 & 45451 & 39533 \\
\hline Maximum length of transcript contig (bp) & 24168 & 15034 & 15005 & 16394 \\
\hline Minimum length of transcript contig (bp) & 400 & 200 & 180 & 300 \\
\hline N50 value & 1205 & 697 & 377 & 1158 \\
\hline Total transcript contig length (in bases) & 38098478 & 23323465 & 16682558 & 34131338 \\
\hline Average transcript contig length (in bases) & 982 & 581 & 367 & 863 \\
\hline CDS statistics & & & & 22599 \\
\hline Total number of CDS & 26569 & 18605 & 28588 & 15279 \\
\hline Maximum length of CDS (in bases) & 15279 & 14997 & 14970 & 297 \\
\hline Minimum length of CDS (in bases) & 297 & 297 & 147 & \\
\hline
\end{tabular}

Susceptible infected (SI), Susceptible uninfected (SU), Resistant infected (RI) and Resistant uninfected (RU).

\section{Functional annotation}

We first annotated the CDS through homologous search against green plant database (txid 33090) of NCBI using BLASTX search and threshold E-value as 1e ${ }^{06}$. A total of 25154 (94.70\%), 17768 (95.50\%), 23605 (82.60\%) and 21255 (94.10\%), respectively in SI, SU, RI and RU had significant BLAST hits (Table 2). Out of the total CDS with blast hits, 5875 (23.3\%) and 710 (3.0\%) CDS in SI and RI respectively were annotated as oomycetes sequences in the nr databases. Based on BLASTX annotation, top hit species with Isabgol transcriptome showed highest similarity to Sesamum indicum (41-59\%) followed by Erythranthe guttata (10-13\%) (Fig. 1) and Cofea conephorea (1-2\%) genomes (Fig. 2). Blast hits were also obtained with Phytophthora parasitica, Phytophthora sojae, Phytophthora infestans and Phytophthora nicotianae, four closely related oomycete species of Peronospora plantaginis in the infected (SI and RI) samples.

Table 2. Distribution of BLAST results of CDS in the leaf transcriptome of Isabgol (Plantago ovata)

\begin{tabular}{|c|c|c|c|c|}
\hline \multirow[t]{2}{*}{ Description } & \multicolumn{4}{|l|}{ Number of CDS } \\
\hline & SI & su & RI & RU \\
\hline Number of CDS with BLAST hits and & $25154(94.70)$ & $17768(95.50)$ & $23605(82.60)$ & $21255(94.10)$ \\
\hline \multicolumn{5}{|l|}{ Per cent of BLAST hits } \\
\hline Number of CDS without BLAST hits & 1415 & 837 & 4983 & 1344 \\
\hline GO distribution of BLAST hits-Biological processes & 10115 & 6945 & 10140 & 8014 \\
\hline GO distribution of BLAST hits-Molecular functions & 7481 & 4977 & 7168 & 5915 \\
\hline GO distribution of BLAST hits-Cellular component & 10745 & 7278 & 10674 & 8357 \\
\hline \multicolumn{5}{|l|}{ Database } \\
\hline KEGG & 6247 & 5266 & 5016 & 6278 \\
\hline COG & 17758 & 12124 & 13488 & 15069 \\
\hline Pfam & 25274 & 15652 & 14134 & 21828 \\
\hline iTAK-Transcripton factors (TFs) & 709 & 471 & 376 & 682 \\
\hline iTAK-Transcripton regulators (TRs) & 331 & 201 & 151 & 283 \\
\hline iTAK-Protein kinases (PKs) & 684 & 508 & 478 & 650 \\
\hline
\end{tabular}

Susceptible infected (SI), Susceptible uninfected (SU), Resistant infected (RI) and Resistant uninfected (RU). Figures in the brackets indicate percentages.

Gene ontology (GO) was used for classification of predicted CDS into functional categories by Blast2GO searches. Function of predicted CDS were classified and each CDS were provided with ontology of defined terms. GO terms of 28341 in SI, 19200 in SU, 27982 in RI and 22286 in RU were enriched in the 
transcriptome of Isabgol. Of the enriched GO terms, 10115 (35.7\%) terms were grouped to Biological process, 7481 (26.4\%) for Molecular function and 10745 (37.9\%) for Cellular component in SI (Table 2 and Fig. 3). While in SU, 6945 (36.2\%) terms were grouped to Biological process, 4977 (25.9\%) for Molecular function and 7278 (37.9\%) for Cellular component. Of the enriched GO terms, 10140 (36.2\%), 7168 (25.6\%) and 10674 (38.1\%) terms, respectively were grouped to biological process, molecular function and cellular component in RI. Similarly, in RU, 8014 (36.0\%), 5915 (26.5\%) and 8357 (37.5\%) terms were grouped to biological process, molecular function and cellular component, respectively. In the biological process category, highest number of CDS were enriched in metabolic process (G0:0008152) group, followed by cellular process (G0:0009987) group (Fig. 3). In the molecular function category, "catalytic activity" (GO: 0003824) and "binding activity" (GO: 0005488) were most abundantly represented. Under the cellular component category, the highest number of CDS were associated with "membrane" (G0:0019898) and "cell" (GO: GO:0005623).

\section{KEGG mapping}

Ortholog assignment and mapping of the CDS to the biological pathways were performed using KEGG automatic annotation server (KAAS) with default score. A total of $6247,5266,5016$ and 6278 CDS were enriched into 41 different functional KASS pathway categories respectively in SI, SU, RI and RU (Additional Table 1). The mapped CDS represented the genes involved in metabolism, genetic information processing, environmental information processing, cellular processes organizational systems and human disease. Metabolic pathways of major biomolecules such as carbon, carbohydrates, lipids, nucleotides, amino acids, glycans, cofactors, vitamins, terpenoids, polyketides and others were mapped in the transcriptome of Isabgol.

To further predict the function, CDS were subjected to classification into different protein families based on Clusters of Orthologus Groups (COG) of protein databases. Overall 17758, 12124, 13488 and 15069 CDS of SI, SU, RI and RU, respectively showed significant homology and assigned to the appropriate COG clusters. The COG annotated putative proteins were distributed functionally into 26 protein families (Fig. 4), of which the cluster for "Signal transduction mechanisms $(T)$ " represented the largest group $(2180,1553,1693$ and 1944 respectively in SI, SU, RI and RU), followed by "General function prediction only $(R)$ " (2007, 1454, 1447 and 1750), "Posttranslational modification, protein turnover, chaperones (o)" (1871, 1262, 1457 and 1505)" in transcriptome of Isabgol. The least represented groups include "multiple functions" (3, 1, 2 and 1 CDS respectively in SI, SU, RI and RU), "cell motility" (8, 5, 5 and 6 CDS) and "Extracellular structures" (87, 51, 47 and 77 CDS) in the transcriptome.

We used InterProscan to see protein similarity at domain level, in total, 25274, 15652, 14134 and 21828 transcripts in SI, SU, RI and RU respectively were annotated against the Pfam domains (Table 2). Pkinase (PF00069) domains represented the most which was followed by PPR (PF01535) and Pkinase_Tyr (PF07714) domains in the Isabgol leaf transcriptome indicating strong signal transduction mechanisms. (Additional Fig. S1, Additional file S1). Transcription factors (TFs) affect metabolic flux by regulating gene expression of key genes involved in the biosynthetic ways. We performed BLASTX search against the known Plant Transcription Factor database using the CDS from SI, SU, RI and RU transcriptomes. A total of 709, 471, 376 and 682 TFs belong to 63 families in SI, SU, RI and RU respectively were annotated (Table 2, Additional file S2). Similarly, we annotated 331, 201, 151 and 283 transcriptional regulators (TRs) belong to 25 families in $\mathrm{SI}, \mathrm{SU}, \mathrm{RI}$ and RU respectively indicates their role in gene expression in Isabgol.

\section{Identification of differentially expressed genes}

The relative expression level of commonly expressed CDS based on common 'nr' blast hit accession in terms of Fragments Per Kilobase of transcripts per Million (FPKM) was estimated by mapping all the clean reads from each library back to CDS. Subsequently, 6928 (15.33\%) CDS were differentially expressed between RU and RI libraries of which 1123 (16.28\%) were significantly up-regulated while 1019 (14.70\%) CDS were significantly down-regulated with P values $\leq 0.05$ solely in RI compared to RU (Table 3). There were 8779 (17.15\%) CDS differentially expressed between libraries SU and SI of which 1408 (16.00\%) CDS were significantly up-regulated while 1201 (13.60\%) were significantly down-regulated with P values $\leq 0.05$ in SI compared to SU (control) (Additional file S3). Heat map of top 50 up-regulated and top 50 down-regulated genes presented in Fig. 5 clearly shows both resistant and susceptible genotypes have some similar responses to PP infection for some DEGs. The data illustrated differences between resistant and susceptible genotypes up on infection of PP fungus and deep analysis of these genes may shed light on the resistance mechanism in Isabgol. However, some of the changes in gene expression may be due to the difference in genetic background of these genotypes. Furthermore, the functional classification of DEGs in leaf transcriptome was analysed using GO (Gene ontology). A total of 1519 and 3455 DEGs respectively in RU vs RI and SU vs SI were enriched to at least one GO term (Fig. 6; Additional file S4). Among the biological processes, where the term occurrences took place, metabolic process (11.06\%) followed by oxidation-reduction process (6.30\%) (Fig. 6) recorded maximum terms enriched. In addition, DEGs involved in biological processes like autophagy, response to stimulus and immune system were recognised through GO annotation. In cellular components, GO terms enriched were "integral to membrane" (37.29\%) followed by "membrane" (7.97\%). In molecular function, GO terms enriched were structural constituent of "ribosome" (2.61\%), "protein kinase activity" (2.70\%) and "protein serine/threonine kinase activity" $(2.21 \%)$.

Table 3. Summary of deferentially expressed genes (DEGs) in the leaf transcriptome of Isabgol (Plantago ovata)

\begin{tabular}{|llllll|}
\hline Control $x$ treated & Total predicted CDS & Total DEGs $(\%)$ & Significant DEGs & Up-regulated genes & Down-regulated genes \\
\hline RU vs RI & 45174 & $6928(15.33)$ & $2142(4.74)$ & $1123(52.42)$ & $1019(47.50)$ \\
\hline SU vs SI & 51187 & $8779(17.15)$ & $2609(5.09)$ & $1408(53.96)$ & $1201(46.04)$ \\
\hline
\end{tabular}

Susceptible infected (SI), Susceptible uninfected (SU), Resistant infected (RI) and Resistant uninfected (RU). Figures in the parenthesis indicate percentages

Metabolic pathway analysis was performed for all DEGs using KEGG automatic server (KAAS) to explore the biochemical pathways in which DEGs involved. The results revealed that, 1209 and 2037 DEGs were assigned to 159 and 215 KEGG pathways in RU vs RI and SU vs SI, respectively. Most DEGs were 
assigned to ribosome [PATH: ko03010], carbon metabolism [PATH: ko01200], oxidative phosphorylation [PATH: ko00190], RNA transport [PATH: ko03013], spliceosome [PATH: ko03040], protein processing in endoplasmic reticulum [PATH: ko04141] and plant hormone signal transduction [PATH: ko04075] pathways. Most importantly, several pathways associated with defense were also enriched by KEGG analysis (Additional file S4).

\section{Mining genes involved in Host-pathogen interaction pathway}

Host plants perceive pathogens by different recognition systems which are accompanied by a set of induced defense to repel pathogen attack. Activation of pattern recognition receptors (PRRs) by pathogen-associated molecular patterns (PAMPs) at the surface of plant elicits a defense programme known as PAMP-triggered immunity (PTI). In plants, there are 25 genes identified to be involved in PTI [6-7]. In the present study, CDS were found for 18 (FLS2, EFR, BAK1, MEKK1, MKK1/2, MKK4/5, WRKY22/29, WRKY25/33, CNGC, CDPK, CaM, CML, RBOH, NOS, RLK1, NHo1, CERK and PTI6) genes involved in PTI indicating their role in plant-pathogen interaction (Additional Table 2 and 3). However, we did not find CDS for CEBiP, FRK1, PR1, Pto, PRF, PTI4 and PTI5 genes involved in conferring PTI in our dataset. Three (WRKY25/33, CDPK and RLK1) genes were significantly up-regulated while the genes ( $F L S 2$, EFR, CNGC and $C a M$ ) were significantly down-regulated in RU vs RI (Fig. 7) indicating their role in PTI in DPO-185 (Resistant) genotype. The genes EFR, BAK1, CaM, CML and RLK1 were significantly up-regulated in SU vs SI indicating their role in PTI in DPO-14 (susceptible) genotype.

Effector-triggered immunity (ETI) is thought to mount a second layer of defense or known as secondary immune response in plants. R-proteins can directly sense pathogen effectors, or they can detect pathogens through other cofactors, which are direct host targets for pathogens. There are genes reported conferring effector-triggered immunity in plants against various pathogens. In the present study, CDS were identified for 15 (RIN4, PBS1, RPM1, RPS1, RAR1, SGT1, HSP90, PIK1, EDS1, HCD1, WRKY1, BS3, WRKY2, KCS1 and FDH) genes involved in ETI (Additional Table 4 and 5; Fig. 7) indicating their role in defense response ETI. However, we did not find CDS for RPS4, UPA20, RRS1-R, MLA10, L6, ATMYB30, UPA7 and RPS5 reported to be involved in conferring ETI in our dataset. Of the 15 genes detected in the leaf transcriptome, FDH gene was significantly up-regulated while the PIK1, WRKY1 and $K C S 1$ genes were significantly down-regulated in RU vs RI in DPO-185 (resistant) indicating their role in ETI. Similarly, the genes RAR1, SGT1 and EDS1 were significantly up-regulated while KCS1 genes were significantly down-regulated in SU vs SI in the DPO-14 (Susceptible) indicating their role in conferring ETI in Isabgol.

\section{Mining genes involved in Cell wall modifying enzymes}

Cell wall forms a dynamic structure that determines the outcome of the interactions between host and pathogens. When pathogens start degrading the plant cell wall components, plants are capable of perceiving the loss of cell wall integrity and subsequently activate the defense signalling pathways. Pathogens try to escape the plant defense and sometimes take advantage of the host cell wall metabolism to facilitate their entry into the tissue. There were five [ $L i p i d$ transfer protein 2 (LPT2), Glutathione S-transferase (GST), Callose synthase (CS), Cinnamyl alcohol dehydrogenase (CAD) and Lignin-forming anionic peroxidase $(L A P)]$ genes encoding the enzymes involved in modifying the cell wall during host-pathogen interaction. In the present study, $C D S s$ were found for $\angle P T 2, G S T, C S$ and $C A D$ and $\angle A P$ genes in the leaf transcriptome indicating their role in host pathogen interaction (Additional Table 6 and 7 ). Further, the genes, $L P T 2, G S T, C S$, and CAD were significantly down-regulated in RU vs RI indicating their expression pattern up on DM infection in DPO-185 (resistant genotype). The gene $L A P$ is significantly up-regulated while the genes $L P T 2$ and $C S$ were significantly down-regulated in SU vs SI in DPO-14 (susceptible genotype). However, the other genes GST and CAD did not shown difference in expression.

\section{Genes involved in Phytohormone signalling}

Phytohormones emerged as cellular signal molecules with key functions in the regulation of immune responses to microbial pathogens and insects. Phytohormones, such as abscisic acid (ABA), ethylene (ET), jasmonic acid (JA), salicylic acid (SA), brassinosteroids (BRs), gibberellic acids (GAs), auxins and cytokinins (CK) act as signalling molecules to triggering immune responses to pathogens in plants. There are 43 genes reported to be involved in phytohormone signalling in plants through various phytohormones (Additional Table 8 and 9; Fig. 8). In the present study, CDS were detected for 32 genes viz., three (PYR/PYL, PP2C and SNRK2) gene involved in ABA signalling, six (ETS/ETR, CTR1, SIMKK, EIN2, EBF1_2 and ERTF1/2) genes involved in ET signalling, four (JAR1, COI-1, JAZ, and MYC2) genes involved in JA signalling, two (NPR1 and TGA) genes involved in SA signalling, five genes in BR (BAK1, BRI1, BKI1, TCH4 and CD3) and four (GID, Della, GID2 and PIF3) gene in GA signalling, six ( $L A X 3, T I R 1, A R P, A R F, G H 3$ and SAUR) genes involved in auxin signalling and two $(A H P 5$ and $A R R-B)$ gene of cytokinins indicating their role in Isabgol and DM interaction. Further, the genes $P Y R / P Y L, P P 2 C, S N R K 2$ of $A B A$ signalling, $T G A$ of SA signalling, GID and GID2 of GA signalling and GH3 of auxin signalling were significantly up-regulated, while NPR1 involved in SA signalling, TCH4 and $C D 3$ of BR signalling, and TIR1, ARF of auxin signalling, and $C R E 1$ and $A R R-B$ of cytokinin were significantly down-regulated in RU vs RI indicating their role in DM infection in DPO-185 (Resistant genotype). Similarly, the genes ETS/ETR and CTR1 of ET signalling, COI-1 of JA signalling, NPR1 of SA signalling, BAK1 and $C D 3$ of $B R$ signalling, ARF of auxin signalling and ARR-B of cytokinin were significantly up-regulated while genes $P Y R / P Y L$ of $A B A$ signalling, ERTF1/2 of ET signalling and BKI1 of BR signalling were significantly down-regulated in SU vs SI indicating their role in conferring DM signalling in DPO-14 (Susceptible genotype).

\section{Genes involved in phenylpropanoid biosynthetic pathway}

Phenylpropanoid biosynthetic pathway is one of the important secondary metabolic pathways which plays important role in plant defense [39]. There were 14 genes involved in phenylpropanoid biosynthetic pathway [39-40]. KEGG annotation of the phenylpropanoid biosynthetic pathway in response to PP infection is presented in Fig. 9. In the present study, CDS were detected for 13 of the 14 genes involved in phenylpropanoid biosynthetic pathway in the leaf transcriptome indicating their role in DM resistance (Additional Table 10 and 11). We didn't find the CDS for UGT72E encoding Coniferyl-alcohol glucosyltransferase involved in phenylpropanoid biosynthetic pathway. The genes $C C R$ and $H C T$ were significantly up-regulated while the genes $C A D$ and REF1 were significantly down-regulated in RU vs RI indicating their role in plant defense up on infection in DPO-185 (resistant genotype). The genes $4 C L$ and CSE were significantly down-regulated in SU vs SI showing their role in conferring the plant defense up on infection in DPO-14 (susceptible genotype). 


\section{Enriched R-Genes in response to DM infection}

According to the gene-for-gene hypothesis, resistance (R) proteins recognize and interact with effectors and trigger ETI [7]. Resistance (R) genes are the members of a large multigene family genes encoding disease resistance proteins in plants. More than 70 different $\mathrm{R}$ genes showing resistance to major plant pathogens have been isolated and characterized in plants [41]. R proteins posses multi-domain structure (Nucleotide-binding site (NBS)-leucine-rich repeat (LRR) (NL), coiled-coil (CC)-NBS-LRR (CNL), Toll Interleukin-1 Receptor (TIR)-NBS-LRR (TNL), nucleotide-binding adaptor shared by apoptotic protease activating factor 1 (NB-ARC), Receptor-like kinases (RLK) and others) which allows simultaneously recognition of Avr proteins of the pathogen and trigger plant defense reactions [42]. In the present study, CDS were found for 58 candidate R genes in the leaf transcriptome indicating their role in conferring DM resistance (Additional Table 12). Of these, 25 encode CNL proteins, 10 encode other, six encode NL, three encode TNL, two encode RLK, and one encode NBARC domain containing proteins. Remaining 11 encode unclassified R proteins. The most represented group of R genes in plants cloned to date are CNL proteins characterized by nucleotide-binding site (NBS) and leucine rich repeat (LRR) domains as well as variable amino- and carboxy-terminal domains. However, only 43 of these genes were differentially expressed (Table 4) in Isabgol transcriptome. There were 10 (Alanine-glyoxylate aminotransferase 2 (At2), NBS type disease resistance protein, NBS-LRR class resistance protein Fy12-Ry1, NBS-LRR class resistance protein Fy1-Ry1, Disease resistance protein RPP13, Late blight resistance protein homolog R1A-10, Late blight resistance protein homolog R1A-3, Late blight resistance protein homolog R1A-4, Late blight resistance protein homolog R1B-16 and Late blight resistance protein homolog R1B-8) R genes significantly up-regulated and 12 (Restricted Tev Movement 2 (RTM2), General transcription factor IIA subunit 2 (TFIIAy), Mildew Locus O (MLO) gene, Disease resistance family protein/LRR family protein, Disease resistance protein RGA2, Late blight resistance protein $R 1-A$, Disease resistance protein At1g58602, Enhanced disease resistance 2, Disease resistance protein At3g14460, Disease resistance protein At3g14460, Disease resistance protein RGA4 and Late blight resistance protein homolog R1C-3) $\mathrm{R}$ genes downregulated in $\mathrm{RU}$ vs $\mathrm{RI}$ indicating their expression up on DM infection in the resistant parent DPO-185. Similarly, there were seven (Resistance to Fusarium oxysporum 1 (RFO-1), General transcription factor IIA subunit 2 (TFIIAy), IAA-alanine resistance protein 1, Disease resistance protein At4g33300, Enhanced disease resistance 2, Disease resistance protein RGA1 and Late blight resistance protein homolog R1B-16) genes significantly up-regulated and 12 ( $P E P 1$ Receptor 1(PEPR1), Late blight resistance protein homolog R1B-14 (SW-5), NBS-LRR class resistance protein Fy8-Ry8, Disease resistance protein RPP13, Disease resistance RPP8, Disease resistance protein RGA3, Putative disease resistance RPP13, Late blight resistance protein homolog R1B-12, Late blight resistance protein homolog R1B-14, Late blight resistance protein homolog R1B-8 and Late blight resistance protein homolog R1C-3) genes down-regulated in SU vs SI showing their expression in the susceptible genotype DPO-14 indicating their role in conferring resistance to DM disease. Interestingly, the Late blight resistance protein homolog R1B-14 (SW-5), R1B-12 and R1B-8 identified as CNL (CC-NBS-LRR) type of R protein were down-regulated 6.32, 6.00 and 8.20 -fold respectively in $\mathrm{SU}$ vs $\mathrm{SI}$, indicating a crucial role in the DM defense response.

Table 4. Differentially expressed R-genes identified in leaf transcriptome of Isabgol (Plantago ovata) 


\begin{tabular}{|c|c|c|c|c|}
\hline \multirow[t]{2}{*}{ S.No. } & \multirow[t]{2}{*}{ R-genes (cloned) } & \multirow[t]{2}{*}{ Gene Id } & \multicolumn{2}{|c|}{$\log _{2}$ fold change values } \\
\hline & & & RUvs RI & SUvs SI \\
\hline 1 & Alternaria stem canker resistance protein (ASC) & XP_011077707 & $\# N / A$ & $\# N / A$ \\
\hline 2 & Restricted Tev Movement 2 (RTM2) & XP_011091969 & -2.305439972 & -0.193337627 \\
\hline 3 & PEP1 Receptor 1(PEPR1) & XP_011080517 & -0.617383978 & -2.012695073 \\
\hline 4 & Resistance to Fusarium oxysporum 1 (RFO-1) & XP_012835527 & 0.33191121 & 2.461446713 \\
\hline 5 & General transcription factor IIA subunit 2 (TFIIAy) & XP_012856602 & -1.220048481 & 1.745157888 \\
\hline 6 & Serine-glyoxylate aminotransferase (At1) & XP_011090165 & 0.020550403 & -0.303689105 \\
\hline 7 & Alanine-glyoxylate aminotransferase 2 (At2) & XP_011080767 & 1.040641984 & -0.024767905 \\
\hline 8 & ABC transporter $G$ family member 35 (Lr34) & XP_011080481 & -0.535611608 & 0.33695378 \\
\hline 9 & MLO (Mildew Locus O) gene & XP_011098016 & -3.151787363 & 0.335446369 \\
\hline 10 & NB-LRR type disease resistance protein (Rps $1-k-1)$ & KRH65532 & $\# \mathrm{~N} / \mathrm{A}$ & $\# \mathrm{~N} / \mathrm{A}$ \\
\hline \multirow[t]{2}{*}{11} & Late blight resistance protein homolog R1B-14 (Sw-5) & XP_011072124 & 0.914259704 & -6.322692958 \\
\hline & R-Genes (Others) & & & \\
\hline 12 & Disease resistance family protein / LRR family protein & XP_007038696 & -2.68055 & $\# \mathrm{~N} / \mathrm{A}$ \\
\hline 13 & Disease resistance protein [Glycine soja] & KHN30606 & $\# \mathrm{~N} / \mathrm{A}$ & $\# \mathrm{~N} / \mathrm{A}$ \\
\hline 14 & Disease resistance protein $R P M 1$ & XP_011089079 & 0.930459 & -0.43654 \\
\hline 15 & $N B-A R C$ domain-containing disease resistance protein & XP_007012768 & $\# \mathrm{~N} / \mathrm{A}$ & $\# \mathrm{~N} / \mathrm{A}$ \\
\hline 16 & NBS resistance protein $R G A 43$ & AKC03708 & $\# N / A$ & $\# \mathrm{~N} / \mathrm{A}$ \\
\hline 17 & NBS type disease resistance protein & ABF81447 & 2.325131 & 0.63691 \\
\hline 18 & NBS-coding resistance gene analog & ACE79511 & $\# N / A$ & $\# \mathrm{~N} / \mathrm{A}$ \\
\hline 19 & NBS-LRR class resistance protein Fy12-Ry1 & AGX27506 & 4.137504 & $\# \mathrm{~N} / \mathrm{A}$ \\
\hline 20 & NBS-LRR class resistance protein Fy12-Ry12 & AGW28126 & $\# N / A$ & $\# \mathrm{~N} / \mathrm{A}$ \\
\hline 21 & NBS-LRR class resistance protein Fy1-Ry1 & AGX27499 & 4.137504 & $\# \mathrm{~N} / \mathrm{A}$ \\
\hline 22 & NBS-LRR class resistance protein Fy8-Ry8 & AGX27504 & $\# N / A$ & -4.417085328 \\
\hline 23 & Disease resistance protein $R G A 2$ & XP_011072600 & -1.66985 & 0.596377 \\
\hline 24 & Disease resistance protein RPM1 & XP_012849603 & -0.12553 & 0.132773 \\
\hline 25 & Disease resistance protein RPS2 & XP_002279295 & $\# N / A$ & $\# N / A$ \\
\hline 26 & Disease resistance protein RPS6 & XP_012829386 & $\# \mathrm{~N} / \mathrm{A}$ & $\# \mathrm{~N} / \mathrm{A}$ \\
\hline 27 & Disease resistance protein $R P P 13$ & XP_012851388 & 2.137504 & -1.36724 \\
\hline 28 & Disease resistance $R P P 8$ & XP_011072174 & 0.485427 & -1.96189 \\
\hline 29 & IAA-alanine resistance protein 1 & XP_011070517 & 0.485427 & 1.208624 \\
\hline 30 & Late blight resistance protein $R 1-A$ & XP_011097122 & -2.12928 & 0.888602 \\
\hline 31 & Disease resistance protein At1g58602 & XP_011091324 & -2.51355 & -0.20903 \\
\hline 31 & Disease resistance protein At4g33300 & XP_011083793 & 0.525741 & 1.451477 \\
\hline 32 & Enhanced disease resistance 2 & XP_011089926 & -3.83404 & 3.290901 \\
\hline 33 & Disease resistance protein At1g50180 & XP_011073815 & 0.904013 & 0.381976 \\
\hline 34 & Disease resistance protein At3g14460 & XP_011089052 & -1.35755 & -0.32865 \\
\hline 35 & Disease resistance protein At5g63020 & XP_010645051 & $\# \mathrm{~N} / \mathrm{A}$ & $\# \mathrm{~N} / \mathrm{A}$ \\
\hline 36 & Disease resistance RPP8 & XP_011072174 & 0.485427 & -1.96189 \\
\hline 37 & Enhanced disease resistance 2 & XP_011078691 & 0.412816 & -0.13334 \\
\hline
\end{tabular}




\begin{tabular}{|c|c|c|c|c|}
\hline 38 & Disease resistance protein At1g50180 & XP_011073815 & 0.904013 & 0.381976 \\
\hline 39 & Disease resistance protein At1g58400 & XP_012829221 & $\# \mathrm{~N} / \mathrm{A}$ & $\# \mathrm{~N} / \mathrm{A}$ \\
\hline 40 & Disease resistance protein At3g14460 & XP_011089052 & -1.35755 & -0.32865 \\
\hline 41 & Disease resistance protein $R G A 1$ & XP_011097211 & -0.66985 & 2.893527 \\
\hline 42 & Disease resistance protein $R G A 3$ & XP_012833088 & 0.067114 & -1.10319 \\
\hline 43 & Disease resistance protein RGA4 & XP_012854094 & -3.6504 & $\# \mathrm{~N} / \mathrm{A}$ \\
\hline 44 & Putative disease resistance RPP13 & XP_011091694 & $\# \mathrm{~N} / \mathrm{A}$ & -3.18827 \\
\hline 45 & Late blight resistance protein homolog R1A-10 & XP_011071970 & 4.055041 & $\# \mathrm{~N} / \mathrm{A}$ \\
\hline 46 & Late blight resistance protein homolog R1A-3 & XP_011072560 & 4.076103 & $\# \mathrm{~N} / \mathrm{A}$ \\
\hline 47 & Late blight resistance protein homolog R1A-4 & XP_011072135 & 4.722466 & $\# N / A$ \\
\hline 48 & Late blight resistance protein homolog R1B-11 & XP_009785700 & $\# \mathrm{~N} / \mathrm{A}$ & $\# \mathrm{~N} / \mathrm{A}$ \\
\hline 49 & Late blight resistance protein homolog R1B-12 & XP_012856432 & $\# \mathrm{~N} / \mathrm{A}$ & -6.00685 \\
\hline 50 & Late blight resistance protein homolog R1B-13 & XP_012853219 & $\# \mathrm{~N} / \mathrm{A}$ & $\# \mathrm{~N} / \mathrm{A}$ \\
\hline 51 & Late blight resistance protein homolog R1B-16 & XP_011088087 & 3.544679 & 2.665655 \\
\hline 52 & Late blight resistance protein homolog R1B-17 & XP_012853777 & $\# N / A$ & $\# \mathrm{~N} / \mathrm{A}$ \\
\hline 53 & Late blight resistance protein homolog R1B-19 & XP_011080908 & -0.16916 & $\# \mathrm{~N} / \mathrm{A}$ \\
\hline 54 & Late blight resistance protein homolog R1B-8 & XP_012833866 & 2.353232 & -8.2017 \\
\hline 55 & Late blight resistance protein homolog R1C-3 & XP_012853759 & -3.53492 & -1.5659 \\
\hline 56 & Disease resistance protein $R G A 3$ & EMT15286 & $\# \mathrm{~N} / \mathrm{A}$ & $\# \mathrm{~N} / \mathrm{A}$ \\
\hline 57 & TIR-NBS-LRR type disease resistance protein & AEL30371 & $\# \mathrm{~N} / \mathrm{A}$ & $\# \mathrm{~N} / \mathrm{A}$ \\
\hline 58 & TMV resistance protein $N$ & KHN11124 & $\# \mathrm{~N} / \mathrm{A}$ & $\# \mathrm{~N} / \mathrm{A}$ \\
\hline
\end{tabular}

Susceptible infected (SI), Susceptible uninfected (SU), Resistant infected (RI) and Resistant uninfected (RU). No change (\#N/A), (-): down regulated.

\section{Realtime Gene expression analysis}

To validate the gene expression profiles from the high throughput RNA sequencing, the transcript levels of 11 DEGs were selected to profile their expression upon DM infection in resistant (DPO-185) and susceptible (DPO-14) genotypes (Table 5). Differential expression of transcripts in RI (infection level: slight (S), medium (M) and high $(\mathrm{H})$ ) and SI (infection level: slight (S), medium (M) and high $(\mathrm{H})$ ) compared to their respective controls (uninfected DM) were found significant. The genes BXL1, TT4, ERF1, ERF, R1B-14 (XP_011072119) and R1B-14 (XP_012833868) in RI and the AUX1 in S/ were upregulated in S, M, H infection levels (Additional file S5; Fig 10). Further, BXL1, ERF1 and ERF genes were down regulated in S, M, $\mathrm{H}$ infection levels in SI. The genes TT4, R1B-14 (XP_011088007) showed upregulation in $\mathrm{S}$, down regulation in $\mathrm{M}$ and upregulation in $\mathrm{H}$ in $\mathrm{SI}$. In contrast, the genes $P R 1$ in both $\mathrm{RI}$ and $\mathrm{SI}$, and $R 1 B-14$ $\left(X P_{-}\right.$011070688) in SI were down regulated in S, upregulated in $\mathrm{M}$ and down regulated in $\mathrm{H}$. The genes AUX1 in RI and R1B-14 (XP_012833868) in SI were upregulated in $\mathrm{S}$ and $\mathrm{M}$, and downregulated in $\mathrm{H}$ infection levels. Whereas the genes CHS, R1B-14 (XP_011070688) and R1B-14 (XP_011088007) were down regulated in infection level $\mathrm{S}$ and upregulated in $\mathrm{M}$ and $\mathrm{H}$ infection levels. Although, RNA-Seq and RT-qPCR methods uses different algorithms to quantify gene expression levels and vast variation of transcript abundance between infected and uninfected as well as between two DPO-14 and DPO-185 exist for some selected genes, some of the tested DEGs showed the consistency in gene expression patterns using qRT-PCR.

Table 5. List of gene specific primers used in RT-qPCR 


\begin{tabular}{|c|c|c|c|c|c|c|c|}
\hline Gene & Name & Forward $(5 \rightarrow 3)$ & Reverse $(5 \rightarrow 3)$ & $\mathrm{Tm}$ & $\begin{array}{l}\text { Expected } \\
\text { product } \\
\text { size (bp) }\end{array}$ & $\begin{array}{l}\text { Observed } \\
\text { product } \\
\text { size (bp) }\end{array}$ & Pathway \\
\hline $\begin{array}{l}\text { Auxin } \\
\text { transporter } \\
\text { protein } 1 \text { (AUX1) }\end{array}$ & XDPOAUX1 & TTTGCATGCACACCACTGTA & AGGGGAAGATAATGGCCAAG & 59.8 & 133 & 130 & $\begin{array}{l}\text { Phytohorm } \\
\text { signaling }\end{array}$ \\
\hline $\begin{array}{l}\text { Beta-D- } \\
\text { xylosidase } 1 \\
\text { (BXL1) }\end{array}$ & XDPOBXL1 & GTCACAAACAAGAGCCTTCTCA & GCTAGGATCACAGGCGAAAG & 59.7 & 100 & 100 & $\begin{array}{l}\text { Secondary } \\
\text { metabolisr }\end{array}$ \\
\hline $\begin{array}{l}\text { Chalcone and } \\
\text { stilbene } \\
\text { synthase (TT4) }\end{array}$ & XDPOTT4 & GTGCGAGAAATCAACGATCA & CCACCACAATGTCCTGTCTG & 59.8 & 122 & 130 & $\begin{array}{l}\text { Secondary } \\
\text { metabolisr }\end{array}$ \\
\hline $\begin{array}{l}\text { Ethylene } \\
\text { responsive } \\
\text { factor(ERF1) }\end{array}$ & XDPOERF1 & CGGTGAGATCTGGTTTGGTT & GCAGAAGTGGTCTTGGAAGC & 59.97 & 148 & 150 & $\begin{array}{l}\text { Phytohorm } \\
\text { signaling }\end{array}$ \\
\hline $\begin{array}{l}\text { Chalcone and } \\
\text { stilbene } \\
\text { synthase (CHS/ } \\
\text { TT4) }\end{array}$ & $\begin{array}{l}\text { XDPOCHS/ } \\
\text { TT4 }\end{array}$ & TGGTTGAGGTCCCAAAACTC & AGGAGCTTGGTGAGCTGGTA & 59.94 & 148 & 150 & $\begin{array}{l}\text { Secondary } \\
\text { metabolisr }\end{array}$ \\
\hline $\begin{array}{l}\text { Pathogen } \\
\text { related protein } 1 \\
\text { (PR1) }\end{array}$ & XDPOPR1 & АACTCTTGCGTTGGAGGAGA & TGGGCCGTAACTGCATATAA & 59.99 & 126 & 120 & $\begin{array}{l}\text { Phytohorm } \\
\text { signaling }\end{array}$ \\
\hline $\begin{array}{l}\text { Ethylene } \\
\text { response } \\
\text { transcription } \\
\text { factor } 7 \text { (ETR1) }\end{array}$ & XDPOERF & TGACAAGCACAGATCCAAGC & CTTCAGGAAAGGGTCACGAA & 59.99 & 169 & 170 & $\begin{array}{l}\text { Phytohorm } \\
\text { signaling }\end{array}$ \\
\hline $\begin{array}{l}\text { Late blight } \\
\text { resistance } \\
\text { protein homolog } \\
\text { R1B-14 } \\
\text { (XP_011070688) }\end{array}$ & Xdaposw5m2 & AATTCCGCCGAGAGAGATTT & AAAGGCCTGTCATCAACTGG & 60.00 & 212 & 200 & $\begin{array}{l}\text { Resistance } \\
\text { gene }\end{array}$ \\
\hline $\begin{array}{l}\text { Late blight } \\
\text { resistance } \\
\text { protein homolog } \\
\text { R1B-14 } \\
\text { (XP_011072119) }\end{array}$ & Xdaposw5m4 & GTGAGGTTATGGAGGGCTGA & ССTTCCTCAACGGATACGAA & 60.00 & 241 & 240 & $\begin{array}{l}\text { Resistance } \\
\text { gene }\end{array}$ \\
\hline $\begin{array}{l}\text { Late blight } \\
\text { resistance } \\
\text { protein homolog } \\
\text { R1B-14 } \\
\text { (XP_012833868) }\end{array}$ & $\begin{array}{l}\text { Xdaposw5- } \\
5770\end{array}$ & TGAGTGTGGCTTCTTATATAGGTTCA & CAATCGCTAAAGGCAGTCCT & 60.00 & 200 & 200 & $\begin{array}{l}\text { Resistance } \\
\text { gene }\end{array}$ \\
\hline $\begin{array}{l}\text { Late blight } \\
\text { resistance } \\
\text { protein homolog } \\
\text { R1B-14 } \\
\text { (XP_011088007) }\end{array}$ & $\begin{array}{l}\text { Xdaposw5- } \\
5970\end{array}$ & TCACAGGTTTGGATGGGTCT & CAATCGCTAAAGGCAGTCCT & 60.00 & 200 & 200 & $\begin{array}{l}\text { Resistance } \\
\text { gene }\end{array}$ \\
\hline
\end{tabular}

\section{Discussion}

Downy mildew (DM) disease caused by Peronospora plantaginis (PP) is most devastating disease of Isabgol. Exploration of host plant resistance has been considered as an attractive and environmentally friendly approach to control DM disease. However, the genetic mechanisms of disease resistance in Isabgol to the pathogen remain unknown. RNA-Seq based transcriptome analysis of DM disease on grape [23-24], pearl millet [27], Arabidopsis [30-31-33], sunflower [43], cucumber [29] and melon [44]. We for the first time identified a stable mutant genotype DPO-185 with resistance of DM disease of Isabgol that could be used as a stable source for resistance in breeding programmes. Further, to understand the genetic mechanisms of resistance, we subjected leaf tissues of infected and control of two mutant genotypes DPO-14 (susceptible to DM) and DPO-185 (resistant to DM) to RNA seq approach to uncover genes and pathways involved in DM resistance. Understanding the molecular mechanism will expedite resistance breeding. The cDNA from infected (I) and uninfected (U) leaves of two mutant genotypes were sequenced using Illumina Hi-seq platform. We obtained $9.738 \mathrm{~GB}$ of raw sequence data which is consistent with the characteristic throughput of Illumina Hi-seq. In general, clean and high-quality reads are essential for good assembly and gene expression analysis [34-45], and hence pre-processing was performed to remove low complexity, low length, duplicate, and rRNA reads and de novo assembled into contigs and further to transcripts and CDS. Trinity assembler was used in the present study. Trinity is the most extensively used to assembler for illumina sequence data [24-25,45]. Trinity uses a novel method for efficient and robust de novo assembly and combines three independent software modules: Inchworm, Chrysalis, and Butterfly, applied sequentially to process large volumes of RNA-seq reads [46]. N50 is an important measure to describe the quality of assembly. Higher the $\mathrm{N}_{50}$ better will be the quality of the assembly. The N50 value found in this study was higher than the previous reports in Isabgol [34], Raphanus sativus (773bp) [45], Camelia sinensis (521bp) [47] and Codonopsis pilosula (1,243bp) [48] infers fairly good assembly of transcriptome of the study. We predicted, 26569, 18605, 28588 and 22599 CDS respectively in SI, SU, RI and RU of Isabgol transcriptome of which more than $90 \%$ have blast hits in 'nr' database of NCBI which is 
comparatively higher than reported in Isabgol [34] and grapes [23-24] and pearl millet [27]. CDS with no annotation might be due to the relatively short length of their assembled sequences or contain untranslated regions, noncoding RNA, short sequence which not contain protein domain.

The largest number (41-59\%) of Isabgol transcripts showed significant similarity with Sesamum indicum followed by Erythranthe guttata and Cofea conephorea genomes. Similarly, Kotwal et al. [34] also found Isabgol transcripts largely aligning to Erythranthe guttata genome. Earlier, Albach et al. [49] and Melotto-Passarin et al. [50], documented the phylogenetic closeness of the family Plantaginaceae (Isabgol) with Pedaliaceae (Sesamum indicum) and Phrymaceae (Erythranthe guttata). However, as expected some transcripts with significant similarity with oomycete (Phytophthora species) genome were observed only in DM infected (SI and RI) samples demonstrated the involvement of PP fungal transcripts in compatible interaction with host [16-27]. Further analysis PP fungal transcripts may help understand the host pathogen interaction pathways.

Gene ontology (GO), is a useful tool to annotate large number of genes and their products and analyze their functions. In the present study, maximum GO terms were assigned for cellular component indicating need for large number of CDS for cellular component activity. Maximum GO terms were assigned for cellular component category in plants such as Humulus lupulus, Brassica rapa, Oryza sativa, Bupleurum chinense, Cassia obtusifolia and Chrysanthemum [51-56]. In the cellular component category, highest number of CDS were associated with "membrane" followed by "cell" in infected and control leaf samples which indicates the need of large number of transcripts for cell structure and maintenance. In contrast, Kotwal et al. [34] observed maximum GO terms associated to nucleus (29.6\%) followed by membrane (17.1\%) in Isabgol. In another study, maximum Go terms associated for "membrane" were reported in transcriptome of Asparagus racemosus [57]. In the biological process category, most of the CDS were associated with "metabolic processes" followed by "cellular process" which may allow for the identification of novel genes and pathways involved in the secondary metabolite pathways leading to host plant resistance. Earlier, maximum GO terms associated for "metabolic process" was reported in the transcriptome of Asparagus racemosus [57]. Under the molecular function category, the largest number of CDS were grouped in the "catalytic activity" followed by "binding activity" and "transporter activity" indicates the dominance of gene regulation, signal transduction and enzymatically active processes in the cell. Earlier, maximum GO terms associated for "catalytic activity" was also reported in Glycyrrhiza uralensis transcriptome [58].

Using KEGG mapping of the best hit CDS, we have identified large number of CDS involved in metabolism, genetic information processing, environmental information processing, cellular processes and organizational systems. Metabolic pathways of major biomolecules such as carbon, carbohydrates, lipids, nucleotides, amino acids, glycans, cofactors, vitamins, terpenoids, polyketides and others were mapped in the transcriptome of Isabgol. These pathways lead to the synthesis of several molecules, which have been reported to confer plant signalling [4], defense [23-27] and resistance to DM disease [23-27, 30-31]. These pathways were also reported to be involved in the biological activity of Isabgol [34,59]. The COG annotated putative proteins were distributed functionally into 26 protein families. Of these cluster for "Signal transduction mechanisms (T)" represented the largest group, followed by "General function prediction only (R)", "Posttranslational modification, protein turnover, chaperones (0)" in transcriptome of Isabgol. The results indicate that genes of signal transduction mechanisms are activated by DM infection. Earlier, Zhou et al. [60] reported the largest cluster for "Signal transduction mechanisms ( $\mathrm{T}$ )" in plants.

The higher number of DEGs identified in the susceptible genotype DPO-14 (8779) compared to the resistant genotype DPO-185 (6928) upon DM infection is consistent with high infection level in DPO-14 resulting in a numerically higher number of transcriptionally modulated genes. Similar findings were observed in Bakanae disease of Rice [53], DM of Pearl millet [27], Cucumber [29] and Grapes [23-24] where the susceptible genotypes depicted more DEGs than the resistant one upon infection.

By bioinformatic analysis of the reads, we provided novel insights into the defense responses of Isabgol to PP infection. Moreover, several metabolic pathways related to plant defense and resistance were significantly enriched in the present study. ETI and PTI provides first line of defense in plants [6-7]. We identified, 18 (FLS2, EFR, BAK1, MEKK1, MKK1/2, MKK4/5, WRKY22/29, WRKY25/33, CNGC, CDPK, CaM, CML, RBOH, NOS, RLK1, NHo1, CERK and PTI6) candidate genes involved in PTI in the leaf transcriptome of Isabgol. Earlier, Chen et al in Brassica rapa [61], Li et al. in Musa acuminate [62], Islam et al. in Lomandra longifolia [63] have identified the gene involved in PTI using transcriptome approach. All these genes have varied expression levels in resistant and susceptible genotypes indicating their role in DM resistance in Isabgol. Some of the PTI genes are up or down regulated in both the mutants (Table 6). Many genes were differentially expressed only in the resistant line, and some genes showed greater variation in the resistant line than that in the susceptible line. The genes, EFR and CaM were up-regulated in DPO-14 (DM susceptible) and down-regulated in DPO-185 (DM resistant) under infected condition when compared uninfected condition which indicates their role in DM defense. Similarly, the gene RLK1 was upregulated in both the mutants under DM infected when compared with uninfected condition. Further, the genes, WRKY and CDPK in DPO-185, BAK1 and CML in DPO-14 were upregulated under DM infection when compared uninfected condition. The gene, FLS2 was down regulated in DPO-185 up on DM infection. Inter-generic transfer of genes encoding PRRs may help engineer broad-spectrum disease resistance in plants. Earlier, heterologous expression of AtEFR in N. benthamiana, tomato, rice, and wheat has enhanced response to several pathogenic bacteria [64-67]. Huibers et al. [30] reported disease-specific expression of host genes during DM infection of Arabidopsis.

In a compatible host-pathogen interaction, the pathogen may secrete effectors into the plant cells to suppress the PTI . However, plants adopt ETI, the second pathogen sensing mechanism to counter pathogenic effectors [6]. During ETI, plants recognize the effectors using a class of protein receptors that contain NB-LRR domains [6-7]. There are 23 genes encoding receptor proteins involved in ETI in plants [6]. We found 15 genes encoding receptor proteins involved in ETI indicating their role in conferring resistance to DM disease. Earlier, Pombo et al. [68] identified various genes involved in ETI in Tomato. Upon PP infection, gene FDH was up-regulated, while the PIK1, WRKY1 and KCS1 were down regulated in resistant parent DPO-185 only. Further, understanding the molecular basis of plant immune responses will pave way for developing disease resistant crop plants.

The cell wall determines the outcome of the interactions between plants and pathogens and pathogens need to breach the cell wall to colonize the plant tissue [69]. Alterations of plant cell wall and degradation of the components are common features of infection by pathogens [70-71]. Alteration in the plant cell wall induces defense responses against invading pathogens [72]. Earlier workers [73] identified the genes Lipid transfer protein 2 (LPT2), Glutathione S-transferase 
(GST), Callose synthase (CS), Cinnamyl alcohol dehydrogenase (CAD) and Lignin-forming anionic peroxidase (LAP) are involved in cell wall degradation during host-pathogen interaction. CDSs were found for $L P T 2, G S T, C S, C A D$ and $\angle A P$ gene in the leaf transcriptome of Isabgol indicating their role in host pathogen interaction. The genes $L P T 2, G S T, C S, C A D$ and $\angle A P$ were significantly down-regulated in DPO-185 (resistant) up on DM infection thus forms an important candidate to study cell wall mediated resistance in Isabgol. The gene $L A P$ is significantly up-regulated while the genes $\angle P T 2$ and $C S$ were significantly down-regulated in DPO-14 (susceptible) compared to DPO-185 (resistant) indicating their role in host-pathogen interaction. Differential expression of genes involved in cell wall degradation during host-pathogen interaction was reported for plant pathogenic oomycetes [74]. Understanding the genes involved in cell wall degradation during host-pathogen interaction will pave way for developing resistance phenotypes with altered cell wall composition.

Phytohormones play key roles in the complex signalling cascades involved in growth, development and defense responses in plants. Plant defense is triggered by synthesis of phytohormones such as jasmonic acid [75], salicylic acid [76], ethylene [75], brassinosteroids [77], gibberellic acids [78], abscisic acid [79], auxins [78] and cytokinins [80] act as signal molecules. There are 43 genes involved in phytohormone signalling in plants through various phytohormones [78] of which CDS were detected for 30 genes in our study which are important candidate genes to uncover the role of phytohormones in DM disease. Several DEGs involving phytohormone signalling found enriched in our study, suggesting their role in DM infection and signalling. For example, $P Y R / P Y L$ gene involved in ABA signalling was up-regulated in DPO-185 (resistant) and down regulated in DPO-14 (susceptible). Similarly, the genes NPR1 of SA signalling, CD3 of BR signalling, ARF on auxin signalling and ARR-B of cytokinin signalling were down-regulated in DPO-185 (resistant) and up-regulated in DPO-14 (susceptible). Earlier, Chen et al. [61] reported up-regulation of both SA and JA pathways in rice (O. meyeriana) after Xoo infection. DEGs of phytohormone synthesis and signalling were also observed in apple upon infection of Pythium [81]. Whether they are response to DM infection is still unknown. Further studies are needed to validate their functions in DM resistance.

The phenylpropanoid pathway serves as a rich source of metabolites in plants, being required for the biosynthesis of lignin, and serving as a starting point for the production of many other important compounds, such as the flavonoids and coumarins which plays important role in plant defense [82-83]. There were 14 genes involved in phenylpropanoid biosynthetic pathway in plants [84]. In the present study, CDS were detected for 13 of the 14 genes involved in phenylpropanoid biosynthetic pathway in the leaf transcriptome. Several differentially expressed genes involving phenylpropanoid biosynthetic pathway were identified (Fig. 9), suggesting their role in conferring DM resistance. The similar results have been reported in many plant-pathogen interactions [40, 83]. The actual role of these genes in conferring the defense mechanism against DM of Isabgol remains to be explored.

Plants have resistance $(\mathrm{R})$ genes whose products mediate resistance to specific microbes or pathogens. The product of $\mathrm{R}$ gene is $\mathrm{R}$ protein that allows recognition of specific pathogen effectors, either through direct binding or by recognition of the effector's alteration of a host protein [8-9]. The $\mathrm{R}$ genes are regarded as the second mechanism of disease resistance in plants [8-9]. R genes occur ubiquitously in the plant kingdom are involved in ETI [41]. More than 70 different $\mathrm{R}$ genes showing resistance to major plant pathogens has been isolated and characterized in different crop plants [41]. However, till date, no reports are on R-genes specific to DM resistance in Isabgol. We found, CDSs for $58 \mathrm{R}$ genes in the leaf transcriptome of Isabgol indicating their role in conferring DM resistance or susceptibility, of which 25 encodes to CNL R-proteins. The most represented group of R genes in plants cloned to date are CNL proteins characterized by nucleotide-binding site (NBS) and leucine rich repeat (LRR) domains as well as variable amino- and carboxy-terminal domains. However, only 43 of these genes were differentially expressed confirming their role in DM resistance. The similar results were reported in plant-pathogen interactions [83]. Identification and molecular charectization of R-genes of plants will help developing disease resistant crops. However, tagging of R-genes identified in this study to DM disease development will help R gene transfer to high yielding genotypes through marker assisted breeding.

\section{Conclusions}

This study for the first time provides the glimpse of transcriptional responses to the DM resistance in Isabgol. The expression data was generated and processed in this study, providing a global and multifaceted overview of Isabgol response to PP, encompassing both susceptible and resistant plant responses in infected and control leaves. We have for the first time identified mutant (DPO-185) resistant to DM disease. Resistant and susceptible lines in Isabgol mutants have different immune responses against DM infection. It is thus valuable considering the obligate nature of the PP fungi and will provide a base for further investigating the molecular mechanisms associated with DM disease resistance in Isabgol and other crops with potential use in Isabgol breeding programmes in the near future.

\section{Methods}

\section{Plant Materials, Growth conditions and Inoculation with pathogen}

Two Isabgol genotypes DPO-14 and DPO-185 were used in the present study. Both are mutants of GI-2, a popular cultivar of Isabgol grown in India and was developed by Anand Agricultural University (AAU), Anand. These mutants DPO-14 and DPO-185 were developed by Ethyl methane sulfonate (EMS) treatment at ICAR-Directorate of Medicinal and Aromatic Plants Research (ICAR-DMAPR), Anand, Gujarat, India. The genotype, DPO-185 is erect, shows distinct yellow leaf tip coloration followed by tip drying during flowering, resistant to DM disease, late maturing (130-140 days) and low yielding. In the contrast, the parent DPO-14 is susceptible to DM disease, early maturing (90-100 days) and high yielding. The pure seeds of DM resistant (DPO-185) and susceptible (DPO-14) genotypes were grown at the research block of ICAR-DMAPR, during 2014-2017 (Four seasons). The genotypes were challenged with the fungal strains causing DM disease during booting to ascertain the disease resistance. The DPO-14 and DPO-185 genotypes were raised in the field during rabi season by following standard package of practices for cultivation of Isabgol [85]. Isolates of $P$. plantaginis were collected from DM lesions on heavily infected Isabgol leaves at ICAR-DMAPR, Anand, Gujarat, India at the time of flowering. The spore suspension (10,000 sporangia per ml) was prepared using distilled water and sprayed on the leaves thrice at 10 days interval from the time of booting to till the completion of flowering. The spraying of spore suspension was carried out in the late evening. The plants were observed daily for symptom development. The disease reactions of the host plants were recorded on day seven after inoculation on 0 to 5 scale through visual observations where 0 : no infected plants, 1: 1-20\% leaf area covered, 2: 21-40\% leaf area covered, 3: 41-60 \% leaf

Page $12 / 26$ 
area covered, 4: 61-80\% leaf area covered, 5: 81-100\% leaf area covered or mortality [86]. Hundred leaves were collected randomly from each entry for scoring the disease. The host plants without fungal inoculation were used as a control. The third leaf from the shoot apex was harvested from three infected and uninfected plants, and the three leaves were combined to represent one replicate. Three independent replicates were collected for each sample for transcriptome analysis.

\section{Total RNA isolation, library construction and deep sequencing}

The infected (I) and uninfected (U) leaves from the DPO-14 (susceptible/S) and DPO-185 (resistant/R) genotypes were used for transcriptome studies. The leaves, resistant uninfected (RU) and resistant infected (RI) of resistant genotype DPO-185, and susceptible uninfected (SU) and susceptible infected (SI) of susceptible genotype DPO-14 were immediately frozen in liquid nitrogen, and then stored in $-80^{\circ} \mathrm{C}$ for isolation of the total RNA. Total RNA from each sample was isolated using Trizol (Invitrogen, Carlsbad, California, United States) according to the standard protocol described by Rama Reddy et al. [5]. The quality of the isolated RNA was checked using $1 \%$ denatured agarose gel (for the presence of $28 \mathrm{~s}$ and $18 \mathrm{~s}$ bands) and quantified using Qubit fluorometer with Quantit dsDNA HS kit (Thermo Fisher Scientific Inc, Waltham, Massachusetts, United States). For RNA library construction and deep sequencing, equal quantity of RNA from infected and uninfected leaf was used. The paired-end cDNA sequencing libraries of infected and uninfected (control) leaf RNA of DPO-185 and DPO-14 were prepared using Illumina TrueSeq Stranded Total RNA HT (with Ribo-Zero plant) Library Preparation Kit per protocol described by the manufacturer (Illumina ${ }^{\circledR}$, San Diego, California, USA). Briefly, rRNA was depleted from total RNA followed by fragmentation. The fragmented rRNA-depleted RNA was converted into first-strand cDNA, followed by second strand CDNA generation, Adapter tailing, adapter ligation and finally ended by index PCR amplification of adaptor-ligated library. Library was quantified on Agilent 2100 bioanlyzer using High Sensitivity DNA Chip (Agilent Technologies, CA, United States) for mean size distribution. The cDNA libraries were sequenced using Illumina Hi-Seq platform (Illumina ${ }^{\circledR}$, San Diego, California, USA). The fluorescent image processing, base-calling and calculation of quality value were performed by illumina data processing pipeline 1.4.

\section{Raw data processing and Annotation}

Next Generation Sequencing (NGS) using Illumina generated raw data in FASTQ format. Quality of the raw data was validated based on Phred quality score (Q). The raw data was filtered and trimmed for low quality score reads, adaptor and primer sequences were removed and reads less than 40 bp were removed using Trimmomatic v0.30 [87]. Sequencing data with Phred quality score $Q \geq 20$ was further used for assembly using Trinity RNA-Sequence assembler (Version 2013) [46] using optimized parameters and K-mer size set to 25. To evalulate the assembly quality, all the paired end reads were aligned back to these contigs by using Bowtie2 program [88]. In-house Perl scripts were used to assess the length distribution of the transcripts, $\mathrm{N}_{50}$ number, average length, maximum length and number of contigs in different intervals. Coding DNA sequences (CDS) from assembled transcript contigs were predicted using Transdecoder (rel16JAN2014) software with default parameters [89]. CDS were functionally annotated by aligning to green plant database of NCBI using basic local alignment search tool (BLASTX) [90] with an E-value threshold of $1 \mathrm{e}^{-06}$. Gene ontology (GO) enrich was calculated using WEGO analysis.

All predicted CDS were annotated against protein database to assign putative function after translation into protein. CDS were searched against the nonredundant protein sequences available in the Uni-ProtKB/SwisProt database using BLASTX with $E$ value threshold of $1 \mathrm{e}^{-06}$. The CDS were categorized in to clusters of phylogenetically wide spread domain families of proteins by comparing the CDS to Clusters of Orthologus Groups (COG) protein database. For the identification of transcription factors, predicted CDS were searched against all the transcription factor and protein kinases at Plant transcription factor database (http://planttfdb.cbi.pku.edu.cn/) using BLASTX with an E-value cut-off of $<1 \mathrm{e}^{-05}$. KEGG automatic annotation server (KAAS) used for ortholog assignment and mapping of CDS to metabolic pathways. BLASTX with threshold bit-score value of 60 (default) was used to search all CDS against the KEGG database (http://www.genome.jp/kegg/). The CDS were mapped in to different functional KASS pathway categories representing different enzymes involved in different metabolic pathways. KAAS (version 1.6) with default parameters was used to perform the KEGG orthology (KO) assignment reconstructions.

\section{Mining genes involved in DM resistance}

To identify putative CDS/transcripts involved in disease resistance, the literature survey was made on functional genes, transcription factors and enzymes involved directly or indirectly in plant disease resistance. Orthologous genes were identified in the annotated CDS using local BLAST search using BioEdit software [91]. Putative R genes were mined from PRGdb (www.prgdb.org) by Blast search. The differentially expressed genes were mapped to biological pathways of plant pathogen interaction pathways: PAMP-triggered immunity (PTI) and Effector-triggered immunity (ETI), cell wall modifying enzymes, phytohormone signaling pathways and phenylpropanoid biosynthetic pathway available in the Kyoto Encyclopaedia of Genes and Genomes (KEGG) database.

\section{Identification of differentially expressed genes}

The relative expression level of commonly expressed CDS based on common 'nr' blast hit in terms of Fragments Per Kilobase of transcripts per Million (FPKM) was computed by mapping all the clean reads from each library back to CDS in the combination as 1) resistant uninfected (RU) vs resistant infected (RI) and 2) susceptible uninfected (SU) vs Susceptible infected (SI). The high-quality reads from each sample were mapped with the respective set of CDS using CLC Genomic workbench to get the read counts which were used in DESeq1 [92] to obtain significantly differentially expressed (DE) genes between infected and control libraries. A complete linkage hierarchical cluster analysis was performed on top 100 differentially expressed genes using multiple experiment viewer (MEV v4.8.1). Levels of expression were represented as $\log _{2}$ ratio of transcript abundance between infected and uninfected (control). Genes were considered significantly differentially expressed only when the fold change was at least one ( $>1$ or $<-1$ in log2 Fold change value), and $P<0.05$. Differentially expressed genes were analyzed by hierarchical clustering. A heat map was constructed using the log-transformed and normalized value of genes based on Pearson uncentered correlation distance as well as based on complete linkage method.

\section{Gene expression studies using RT-qPCR}


Eleven differentially expressed genes involved in plant defence were selected to study expression under DM infected and uninfected condition by real-time quantitative PCR (RT-qPCR). We used the ubiquitin gene as a constitutive expression control. The primers were designed using primer3 software [93] with default parameters. The expected allele size range given was 100-200bp. Total RNA were isolated from the uninfected control and infected (slight (s) -just appearance of PP mycelia on the leaf, moderate (m) -a few prominent ash-coloured DM growth found sporadically on the leaf and high ( $\mathrm{h}$ )-dense ash-coloured DM colonies across the leaf) of DPO-14 (susceptible) and DPO-185 (resistant) genotypes as described above. cDNA was synthesized using oligo (dT) as primers by M-MLV reverse transcriptase (Thermo scientific, Waltham, Massachusetts, USA) according to the manufacturer's instructions. Real-time PCR were performed in a $25 \mu$ l volume using SYBR premix (Genetix, Delhi, India) on the CFX Connect Real-time PCR detection system (Bio-Rad, Hercules, USA). The cycling conditions for quantitative PCR was $5 \mathrm{~min}$ at $95^{\circ} \mathrm{C}$; followed by 35 cycles of amplification with denaturation for $5 \mathrm{~s}$ at $95^{\circ} \mathrm{C}$, annealing for $30 \mathrm{~s}$ at $55^{\circ} \mathrm{C}$, and extension for $20 \mathrm{~s}$ at $72^{\circ} \mathrm{C}$. Triplicate under identical conditions were synchronously performed for all selected genes and control genes. The relative expression values of each transcript were then calculated by the delta-delta $\mathrm{Ct}\left(2^{-\Delta \Delta C t}\right)$ method [94].

\section{Declarations}

\section{Availability of data and materials}

The datasets supporting the results of this article are available at the National Center for Biotechnology Information (NCBI) BioProject database (Short Read Archive) under accession number PRJNA382334 and the Transcriptome Shotgun Assembly (TSA) at DDBJ/EMBL/GenBank under the accession GFNS00000000. The version described in this paper is the first version, GFNS00000000. The materials used in the study are available at ICAR-Directorate of Medicinal and Aromatic Plants Research, Boriavi, Anand, Gujarat, India.

\section{Competing interests}

The authors declare that they have no competing interests

\section{Author's contributions}

Conceived and designed the experiments: NRRR MP. Performed the experiments: NRRR JM. Analyzed the data: NRRR MP JK. Contributed reagents/materials/analysis tools: NRRR MP JK. Wrote the paper: NRRR MP. All authors have read and approved the manuscript.

\section{Acknowledgments}

The authors gratefully acknowledge the Department of Science and Technology (DST), Government of India (GOI), under the grants numbers SERB/EMR/2014/000317 and SERB/EEQ/2016/000693, and Indian Council of Agricultural Research (ICAR), Ministry of Agriculture and Farmers Welfare, Government of India for financially supporting this work. The Director, ICAR-Directorate of Medicinal and Aromatic Plants Research, Boriavi, Anand, Gujarat, India and Indian Council of Agricultural research (ICAR), Ministry of Agriculture and Farmers Welfare, Government of India for the facilities to undertake the study. Authors express sincere thanks to Dr. N. Rama Swamy, Department of Biotechnology, Kakatiya University, Warangal-506009, Telangana, India and Dr. A. Gnanamani, Head \& Senior Scientist, Microbiology Division, Central Leather Research Institute, Adyar, Chennai 600 020, Tamil Nadu, India for their critical comments on the manuscript.

\section{Ethics approval and consent to participate}

Not applicable.

\section{Consent for publication}

Not applicable.

\section{Abbreviations}

Downy mildew (DM), Coding DNA sequence (CDS), Resistant uninfected (RU), Resistant infected (RI), Susceptible uninfected (SU), Susceptible infected (SI), Differentially expressed genes (DEGs), Pattern recognition receptors (PRRs), Pathogen-associated molecular patterns (PAMPs), PAMP-triggered immunity (PTI), Pathogenesis related (PR), Hypersensitive response (HR), Directorate Plantago Ovata (DPO), KEGG automatic annotation server (KAAS), Clusters of Orthologus Groups (COG), Transcriptional regulators (TRs), Fragments Per Kilobase of transcripts per Million (FPKM), Resistance (R) and Realtimequantitative polymerase chain reaction (RT-qPCR)

\section{References}

1. Dhar MK, Kaul S, Sharma P, Gupta M. Plantago ovata: cultivation, genomics, chemistry and therapeutic applications. In: Singh RJ, editor. Genetic resources, chromosome engineering and crop improvement. CRC Press 2011; New York, USA.

2. Janakiram T, Nagaraja Reddy R, Manivel P, Satyajit Roy. Road Map for Isabgol promotion in India, ICAR-Directorate of Medicinal and Aromatic Plants Research, Anand, Gujarat. 2019; 50pp.

3. Dhar MK, Fuchs J, Houben A. Distribution of eu- and heterochromatin in Plantago ovata. Cytogenet Genome Res. 2009; 125(3):235-240.

4. Mehta RH, Ponnuchamy M, Kumar J, Reddy NR. Exploring drought stress-regulated genes in senna (Cassia angustifolia Vahl.): a transcriptomic approach. Funct Integr Genomics. 2017; 17:1-25. 
5. Rama Reddy, N R, Mehta, R H, Soni, P H, Makasana, J, Gajbhiye, N A, Ponnuchamy, M, Kumar J. Next generation sequencing and transcriptome analysis predicts biosynthetic pathway of sennosides from Senna (Cassia angustifolia Vahl.), a non-model plant with potent laxative properties. PLoS one. 2015; 10(6): e0129422.

6. Jones JD, Dangl JL. The plant immune system. Nature. 2006; 444:323-329.

7. Dodds PN, Rathjen JP. Plant immunity: towards an integrated view of plant-pathogen interactions. Nat Rev Genet. 2010; 11(8):539-548.

8. Heath MC. Non-host resistance and non-specific plant defense. Curr Opin Plant Biol. 2000; 3: 315-319.

9. Cui H, Tsuda K, Parker JE. Effector-Triggered immunity: from pathogen perception to robust defense. Annu Rev Plant Biol. 2015; 66:487-511.

10. De Vleesschauwer D, Xu J, Höfte M. Making sense of hormone-mediated defense networking: from rice to Arabidopsis. Front Plant Sci. $2014 ; 5: 611$.

11. Huckelhoven, R. Cell wall-associated mechanisms of disease resistance and susceptibility. Annu Rev Phytopathol. 2007; 45: 101-127.

12. van Loon LC, Rep, M, Pieterse, CM. Significance of inducible defense-related proteins in infected plants. Annu Rev Phytopathol. 2006; 44:135-162 .

13. Greenberg JT, Yao, N. The role and regulation of programmed cell death in plant-pathogen interactions. Cell Microbiol. 2004; 6(3): 201-211.

14. Mandal K, Saravanan R, Maiti S, Kothari IL. Effect of downy mildew disease on photosynthesis and chlorophyll fluorescence in Plantago ovata Forsk. J Plant Dis Protect. 2009; 16 (4):164-168.

15. Mandal K, Patel PR, Maiti S, Kothari IL. Induction of male and female sterility in Isabgol (Plantago ovata) due to floral infection of downy mildew (Pernospora plantaginis). Biologia. 2010; 65:17-22.

16. Fawke S, Doumane M, Schornack S. Oomycete interactions with plants: infection strategies and resistance principles. Microbiol Mol Biol Rev. 2015; 79(3):263-280.

17. Mandal K, Geetha KA. Floral infection of downy mildew of Isabgol. J Mycol PI Path. 2001; 31:355-357.

18. Mandal K, Gajbhiye NA, Maiti S. Fungicidal management of downy mildew of Isabgol (Plantago ovata) simulating farmers field conditions. Australas Plant Pathol. 2007; 36:186-190.

19. Thakur RP, Mathur K. Downy mildews of India. Crop Protection. 2002; 21: 333-345.

20. George ML, Prasanna BM, Rathore RS, Setty TA, Kasim F, Azrai M, Vasal S, Balla O, Hautea D, Canama A, Regalado E, Vargas M, Khairallah M, Jeffers D, Hoisington D. Identification of QTLs conferring resistance to downy mildews of maize in Asia. Theor Appl Genet. 2003;107(3):544-551.

21. Jampatong C, Jampatong S, Jompuk C, Sreewongchai T, Grudloyma P, Balla C, Prodmatee N Mapping of QTL affecting resistance against sorghum downy mildew (Peronosclerospora sorghi) in maize (Zea mays L). Maydica. 2012; 58:119-126.

22. Wang Z, Gerstein M, Snyder M. RNA-seq: a revolutionary tool for transcriptomics. Nat Rev Genet. 2009;10: 57-63.

23. Polesani M, Bortesi L, Ferrarini A, Zamboni A, Fasoli M, Zadra C, Lovato A, Pezzotti M, Delledonne M, Polverari A. General and species-specific transcriptional responses to downy mildew infection in a susceptible (Vitis vinifera) and a resistant (V riparia) grapevine species. BMC Genomics. 2010;11:117.

24. Perazzolli M, Moretto M, Fontana P, Ferrarini A, Velasco R, Moser C, Delledonne M, Pertot I. Downy mildew resistance induced by Trichoderma harzianum T39 in susceptible grapevines partially mimics transcriptional changes of resistant genotypes. BMC Genomics. 2012; 13:660.

25. Li X, Wu J, Yin L, Zhang Y, Qu J, Lu J. Comparative transcriptome analysis reveals defense-related genes and pathways against downy mildew in Vitis amurensis grapevine. Plant Physiol Biochem. 2015; 95:1-14.

26. Lenzi L, Caruso C, Bianchedi PL, Pertot I, Perazzolli M. Laser microdissection of grapevine leaves reveals site-specific regulation of transcriptional response to Plasmopara viticola. Plant Cell Physiol. 2016; 57(1): 69-81.

27. Kulkarni KS, Zala HN, Bosamia TC, Shukla YM, Kumar S, Fougat RS, Patel MS, Narayanan S, Joshi CG. De novo transcriptome sequencing to dissect candidate genes associated with pearl millet-downy mildew (Sclerospora graminicola Sacc.) interaction. Front Plant Sci. $2016 ; 7: 847$.

28. Li J, Ding Q, Wang F, Li H, Zhang Y, Liu L, Jiao Z, Gao J. Genome-wide gene expression profiles in response to downy mildew in Chinese cabbage (Brassica rapa L. ssp. pekinensis). Eur J Plant Pathol. 2018; 151: 861-873.

29. Burkhardt A, Day B. Transcriptome and small RNAome dynamics during a resistant and susceptible interaction between cucumber and downy mildew. Plant Genome. 2016; 9:1.

30. Huibers RP, de Jong, M, Dekter, RW, Van den Ackerveken, G. Disease-specific expression of host genes during downy mildew infection of Arabidopsis. Mol Plant Microbe Interact. 2009; 22(9):1104-1115.

31. Krasileva KV, Zheng C, Leonelli L, Goritschnig S, Dahlbeck D, Staskawicz BJ. Global analysis of Arabidopsis/downy mildew interactions reveals prevalence of incomplete resistance and rapid evolution of pathogen recognition. PLoS One. 2011; 6(12): e28765.

32. Caillaud M, Asai S, Rallapalli G, Piquerez S, Fabro G, Jones JD. A downy mildew effector attenuates salicylic acid-triggered immunity in Arabidopsis by interacting with the Host Mediator Complex. PLoS Biology. 2013:11(12): e1001732.

33. Coker TL, Cevik V, Beynon JL, Gifford ML. Spatial dissection of the Arabidopsis thaliana transcriptional response to downy mildew using fluorescence activated cell sorting. Front Plant Sci. 2015; 6:527.

34. Kotwal S, Kaul S, Sharma P, Gupta M, Shankar R, Jain M, Dhar MK. De novo transcriptome analysis of medicinally important Plantago ovata using RNASeq. PLoS One. 2016: 11(3): e0150273.

35. Jensen JK, Johnson N, Wilkerson, CG. Discovery of diversity in xylan biosynthetic genes by transcriptional profiling of a heteroxylan containing mucilaginous tissue. Front Plant Sci. 2013; 4: 183

36. Fougat RS, Joshi CG, Kulkarni KS, Kumar S, Patel A, Sakure AA, Mistry JG. Rapid development of microsatellite markers for Plantago ovata Forsk. using next generation sequencing and their cross-species transferability. Agriculture. 2014; 4:199-216.

Page $15 / 26$ 
37. Pommerrenig, B, Barth I, Niedermeier M, Kopp S, Schmid J, Dwyer RA, McNair RJ, Klebl F, Sauer N. Common plantain: A collection of expressed sequence tags from vascular tissue and a simple and efficient transformation method. Plant Physiol. 2006: 142(4):1427-41.

38. Pommerrenig B, Feussner K, Zierer W, Rabinovych V, Klebl F, Feussner I, Sauer N. Phloem-specific expression of Yang cycle genes and identification of novel Yang cycle enzymes in Plantago and Arabidopsis. Plant Cell. 2011; 23(5):1904-1919.

39. Vogt T. Phenylpropanoid biosynthesis. Mol Plant. 2010; 3(1):2-20.

40. Ali MB, McNear DH. Induced transcriptional profiling of phenylpropanoid pathway genes increased flavonoid and lignin content in Arabidopsis leaves in response to microbial products. BMC Plant Biol. 1990; 14:1.

41. Sanseverino W, Roma G, De Simone M, Faino L, Melito S, Stupka E, Frusciante L, Ercolano MR. PRGdb: a bioinformatics platform for plant resistance gene analysis. Nucleic Acids Res. 2010; 38 (Database issue): D814-21.

42. Ye J, Fang L, Zheng H, Zhang Y, Chen J, Zhang Z, Wang J, Li S, Li R, Bolund L, Wang J. WEGO: a web tool for plotting GO annotations. Nucleic Acids Res. 2006; 34: 293-297.

43. Qi LL, Long, YM, Jan, CC, Ma, GJ, Gulya, TJ. $\mathrm{PI}(17)$ is a novel gene independent of known downy mildew resistance genes in the cultivated sunflower (Helianthus annuus L.). Theor Appl Genet. 2015; 128(4):757-67.

44. Taler D, Galperin M, Benjamin I, Cohen Y, Kenigsbuch, D. Plant R genes that encode photorespiratory enzymes confer resistance against disease. Plant Cell. 2001; 16: 172-184.

45. Wu G, Zhang L, Yin Y, Wu J, Yu L, Zhou Y, Li M. Sequencing, de novo assembly and comparative analysis of Raphanus sativus transcriptome. Front Plant Sci. 2015; 6: 198.

46. Grabherr, MG, Haas BJ, Yassour M, Levin JZ, Thompson DA, Amit I, Adiconis X, Fan L, Raychowdhury R, Zeng Q, Chen Z, Mauceli E, Hacohen N, Gnirke A, Rhind N, di Palma F, Birren BW, Nusbaum C, Lindblad-Toh K, Friedman N, Regev A. Full-length transcriptome assembly from RNA-Seq data without a reference genome. Nat Biotechnol. 2011; 29(7): 644-652.

47. Wang YN, Tang L, Hou Y, Wang P, Yang H, Wei CL. Differential transcriptome analysis of leaves of tea plant (Camellia sinensis) provides comprehensive insights into the defense responses to Ectropis oblique attack using RNA-Seq. Funct Integr Genomics. 2016: 16(4):383-398.

48. Gao JP, Wang D, Cao LY, Sun HF. Transcriptome sequencing of Codonopsis pilosula and identification of candidate genes involved in polysaccharide biosynthesis. PLoS One. 2015;10(2), e0117342.

49. Albach DC, Meudt HM, Oxelman B. Piecing together “New” Plantaginaceae. Am J Bot. 2005; 92:297-315.

50. Melotto-Passarin DM, Berger IJ, Dressano K, De Martin VF, Oliveira GCX, Bock R, Carrer H. Phylogenetic relationships in Solanaceae and related species based on cpDNA sequence from plastid trnE-trnT region. Crop Breed Appl Biotechnol. 2008; 8:85-95.

51. Progar V, Jakše J, Štajner N, Radišek S, Javornik B, Berne S. Comparative transcriptional analysis of hop responses to infection with Verticillium nonalfalfae. Plant Cell Rep. 2017; 10:1599-1613.

52. Miyaji N, Shimizu M, Miyazaki J, Osabe K, Sato M, Ebe Y, Takada S, Kaji M, Dennis ES, Fujimoto R, Okazaki K. Comparison of transcriptome profiles by Fusarium oxysporum inoculation between Fusarium yellows resistant and susceptible lines in Brassica rapa L. Plant Cell Rep. 2017: $36(12): 1841-1854$.

53. Matić S Bagnaresi P, Biselli C, Orru' L, Amaral Carneiro G, Siciliano I, Valé G, Gullino ML, Spadaro D. Comparative transcriptome profiling of resistant and susceptible rice genotypes in response to the seedborne pathogen Fusarium fujikuroi. BMC Genomics. 2016;17: 608.

54. Sui C, Zhang J, Wei J, Chen S, Li Y, Xu J, Jin Y, Xie C, Gao Z, Chen H, Yang C, Zhang Z, Xu Y. Transcriptome analysis of Bupleurum chinense focusing on genes involved in the biosynthesis of saikosaponins. BMC Genomics. 2011:12: 539.

55. Liu Z, Song T, Zhu Q, Wang W, Zhou J, Liao H. De novo assembly and analysis of Cassia obtusifolia seed transcriptome to identify genes involved in the biosynthesis of active metabolites. Biosci Biotechnol Biochem. 2014; 78(5): 791-9.

56. Xu Y, Gao S, Yang Y, Huang M, Cheng L, Wei Q, Fei Z, Gao J, Hong B. Transcriptome sequencing and whole genome expression profiling of chrysanthemum under dehydration stress. BMC Genomics. 2013; 14: 662.

57. Upadhyay S, Phukan, UJ, Mishra, S, Shukla, RK. De novo leaf and root transcriptome analysis identified novel genes involved in steroidal sapogenin biosynthesis in Asparagus racemosus. BMC Genomics. 2014;15:746.

58. Ramilowski JA. Glycyrrhiza uralensis transcriptome landscape and study of phytochemicals. Plant Cell Physiol. 2013; 54:697-710.

59. Dhar MK, Kaul S, Sareen S, Koul AK. Plantago ovata: genetic diversity, cultivation, utilization and chemistry. Plant Genet Res. 2005; 3(2):252-263.

60. Zhou Y, Chen L, Fan, X, Bian, Y. De novo assembly of Auricularia polytricha transcriptome using Illumina sequencing for gene discovery and SSR marker identification. PLoS One. 2014; 9(3): e91740.

61. Chen J, Pang W, Chen B, Zhang C, Piao Z. Transcriptome analysis of Brassica rapa near-isogenic lines carrying clubroot-resistant and-susceptible alleles in response to Plasmodiophora brassicae during Early Infection. Front Plant Sci. 2016; 6:1183.

62. Li CY, Deng GM, Yang J, Viljoen A, Jin Y, Kuang RB, Zuo CW, Lv ZC, Yang QS, Sheng O, Wei YR, Hu CH, Dong T, Yi GJ. Transcriptome profiling of resistant and susceptible Cavendish banana roots following inoculation with Fusarium oxysporum f. sp. cubense tropical race 4. BMC Genomics. $2012 ; 13: 374$.

63. Islam MT, Hussain HI, Rookes JE, Cahill DM. Transcriptome analysis using RNA-Seq of Lomandra longifolia roots infected with Phytophthora cinnamomi reveals the complexity of the resistance response. Plant Biol (Stuttg). 2018; 20(1):130-142.

64. Lacombe S, Rougon-Cardoso A, Sherwood E, Peeters N, Dahlbeck D, van Esse HP, Smoker M, Rallapalli G, Thomma BP, Staskawicz B, Jones JD, Zipfel C. Interfamily transfer of a plant pattern-recognition receptor confers broad-spectrum bacterial resistance. Nat Biotechnol. 2010; 28(4): 365-369.

65. Zipfel C, Kunze G, Chinchilla D, Caniard A, Jones JD, Boller T, Felix G. Perception of the bacterial PAMP EF-Tu by the receptor EFR restricts agrobacteriummediated transformation. Cell. 2006; 125:749-760. 
66. Schoonbeek HJ, Wang HH, Stefanato FL, Craze M, Bowden S, Wallington E, Zipfel C, Ridout CJ. Arabidopsis EF-Tu receptor enhances bacterial disease resistance in transgenic wheat. New Phytol. 2015; 206(2): 606-13.

67. Schwessinger B, Bahar O, Thomas N, Holton N, Nekrasov V, Ruan D, Canlas PE, Daudi A, Petzold CJ, Singan VR, Kuo R, Chovatia M, Daum C, Heazlewood JL, Zipfel C, Ronald PC. Transgenic expression of the dicotyledonous pattern recognition receptor EFR in rice leads to ligand-dependent activation of defense responses. PLoS Pathog. 2015; 11(3): e1004809.

68. Pombo MA, Zheng Y, Fernandez-Pozo N, Dunham DM, Fei Z, Martin GB. Transcriptomic analysis reveals tomato genes whose expression is induced specifically during effector-triggered immunity and identifies the Epk1 protein kinase which is required for the host response to three bacterial effector proteins. Genome Biol. 2014; 15(10):492.

69. Bellincampi D, Cervone F, Lionetti V. Plant cell wall dynamics and wall-related susceptibility in plant-pathogen interactions. Front Plant Sci. $2014 ;$ 5:228.

70. Cantu D, Vicente AR, Labavitch JM, Bennett AB, Powell AL. Strangers in the matrix: plant cell walls and pathogen susceptibility. Trends Plant Sci. 2008;13(11):610-7.

71. Underwood W, Somerville SC. Focal accumulation of defences at sites of fungal pathogen attack. J Exp Bot. 2008; 59(13): 3501-3508.

72. Serrano M, Coluccia, F, Torres, M, L'Haridon, F, Metraux, JP. The cuticle and plant defense to pathogens. Front Plant Sci. $2014 ; 5: 274$.

73. Łaźniewska J, Macioszek VK, Kononowicz AK. Plant-fungus interface: the role of surface structures in plant resistance and susceptibility to pathogenic fungi. Physiol Mol Plant Pathol. 2012; 78: 24-30.

74. Adhikari BN, Hamilton JP, Zerillo MM, Tisserat N, Lévesque CA, Buell CR. Comparative genomics reveals insight into virulence strategies of plant pathogenic oomycetes. PLoS One. 2013; 8:10.

75. Lorenzo O, Piqueras R, Sánchez-Serrano JJ, Solano R. ETHYLENE RESPONSE FACTOR1 integrates signals from ethylene and jasmonate pathways in plant defense. Plant Cell. 2003;15(1):165-78.

76. Dong X, Hong Z, Chatterjee J, Kim S, Verma DP. Expression of callose synthase genes and its connection with Npr1 signaling pathway during pathogen infection. Planta. 2008; 229(1):87-98.

77. Vidhyasekaran P. Brassinosteroid signaling in plant immune system. In, Plant Hormone Signaling Systems in Plant Innate Immunity. 2015; 2:403-444.

78. Cernadas RA, Benedetti CE. Role of auxin and gibberellin in citrus canker development and in the transcriptional control of cell-wall remodeling genes modulated by Xanthomonas axonopodis pv. citri. Plant Sci. 2009; 177:190-195.

79. Adie BA, Pérez-Pérez J, Pérez-Pérez MM, Godoy M, Sánchez-Serrano JJ, Schmelz EA, Solano R. ABA is an essential signal for plant resistance to pathogens affecting JA biosynthesis and the activation of defenses in Arabidopsis. Plant Cell. 2007; 19(5):1665-1681.

80. Hann CT, Bequette CJ, Dombrowski JE, Stratmann JW. Methanol and ethanol modulate responses to danger- and microbe-associated molecular patterns. Front Plant Sci. 2014; 5:550.

81. Zhu Y, Shao J, Zhou Z, Davis RE. Comparative Transcriptome analysis reveals a preformed defense system in apple root of a resistant genotype of G.935 in the absence of pathogen. Int J Plant Genomics. 2017; 2017:8950746.

82. Dixon RA, Achnine L, Kota P, Liu C-J, Srinivasa, MS, Wang L. The phenylpropanoid pathway and plant defence-a genomics perspective. Mol Plant Pathol. 2002; 3:371-390.

83. Cheng XJ, He B, Chen L, Xiao SQ, Fu J, Chen Y, Yu TQ, Cheng ZQ, Feng H. Transcriptome analysis confers a complex disease resistance network in wild rice Oryza meyeriana against Xanthomonas oryzae pv. oryzae. Sci Rep. 2016; 6: 38215.

84. Fraser, CM, Chapple C. The Phenylpropanoid Pathway in Arabidopsis. The Arabidopsis Book /American Society of Plant Biologists. $2011 ; 9$ : e0152.

85. Jat RS, Nagaraja Reddy R, Ruchi Bansal, Manivel P. Good agricultural practices for cultivation of Isabgol. ICAR-Directorate of Medicinal and Aromatic Plants Research, Boriavi, Anand, Gujarat. 2015. 1-10pp.

86. Rathore BS, Pathak VN. Management of downy mildew of blond psyllium through seed treatment-cum-foliar sprays. Indian Phytopathology. 2001; 54:465-468.

87. Bolger AM, Lohse M, Usadel B. Trimmomatic: a flexible trimmer for Illumina sequence data. Bioinformatics. 2014; 30(15):2114-20.

88. Langmead B, Salzberg SL. Fast gapped-read alignment with Bowtie 2. Nat Methods. 2012; 9(4):357-359.

89. Haas BJ, Papanicolaou A, Yassour M, Grabherr M, Blood PD, Bowden J, Couger MB, Eccles D, Li B, Lieber M, MacManes MD, Ott M, Orvis J, Pochet N, Strozzi F, Weeks N, Westerman R, William T, Dewey CN, Henschel R, LeDuc RD, Friedman N, Regev A. De novo transcript sequence reconstruction from RNA-seq using the Trinity platform for reference generation and analysis. Nat Protoc. 2013; 8:1494-1512.

90. Altschul SF, Gish W, Miller W, Myers EW, Lipman DJ. Basic local alignment search tool. J Mol Biol. 1990; 215(3):403-10.

91. Hall TA. BioEdit: A User-Friendly Biological Sequence Alignment Editor and Analysis Program for Windows 95/98/NT. Nucleic Acids Symposium Series. 1999; 41: 95-98.

92. Wang L, Feng Z, Wang X, Wang X, Zhang X. DEGseq: an R package for identifying differentially expressed genes from RNA-seq data. Bioinformatics. 2010; 26:136-138.

93. Untergasser A, Cutcutache I, Koressaar T, Ye J, Faircloth BC, Remm M, Rozen SG. Primer3 - new capabilities and interfaces. Nucleic Acids Res. 2012; 40(15): e115.

94. Livak KJ, Schmittgen TD. Analysis of relative gene expression data using real-time quantitative PCR and the 2(-Delta Delta C(T)) Method. Methods. 2001; 25(4): 402-408.

\section{Figures}

Page $17 / 26$ 


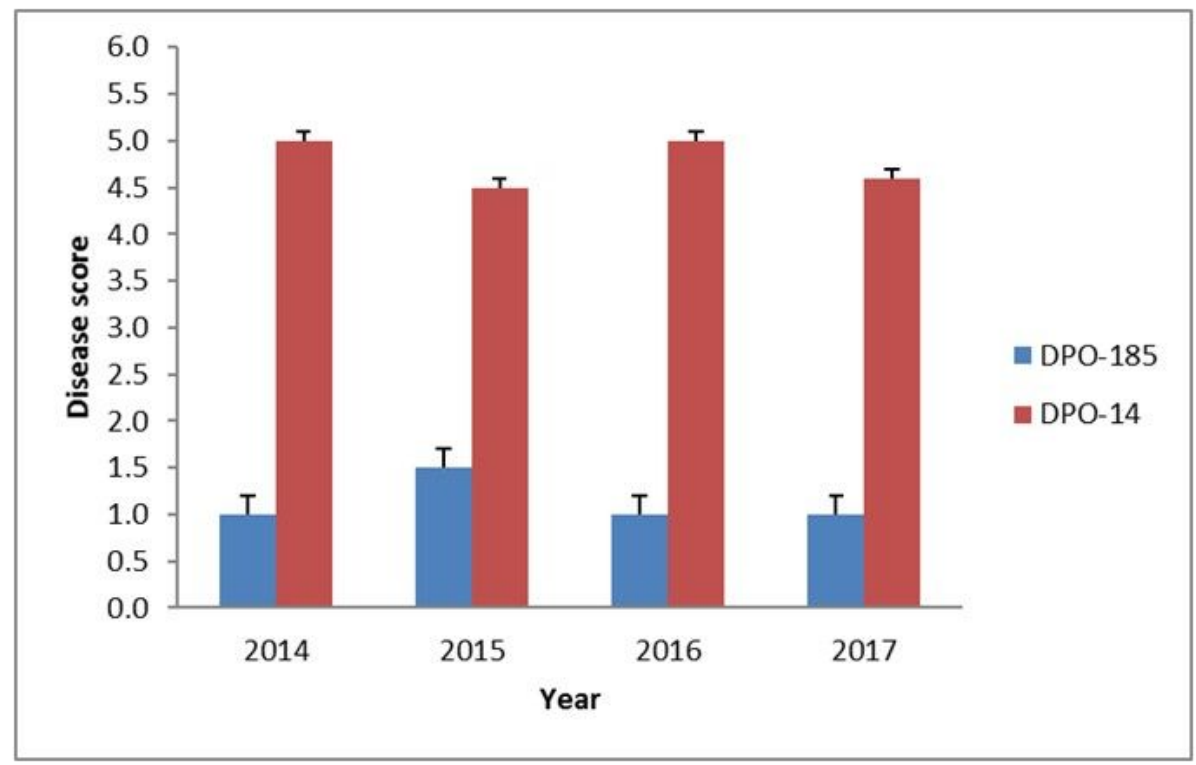

Figure 1

Downy mildew disease reaction of Isabgol genotypes. Disease score in 0-5 scale, where 0: Healthy plants and 5: more than $80 \%$ leaf area covered. 

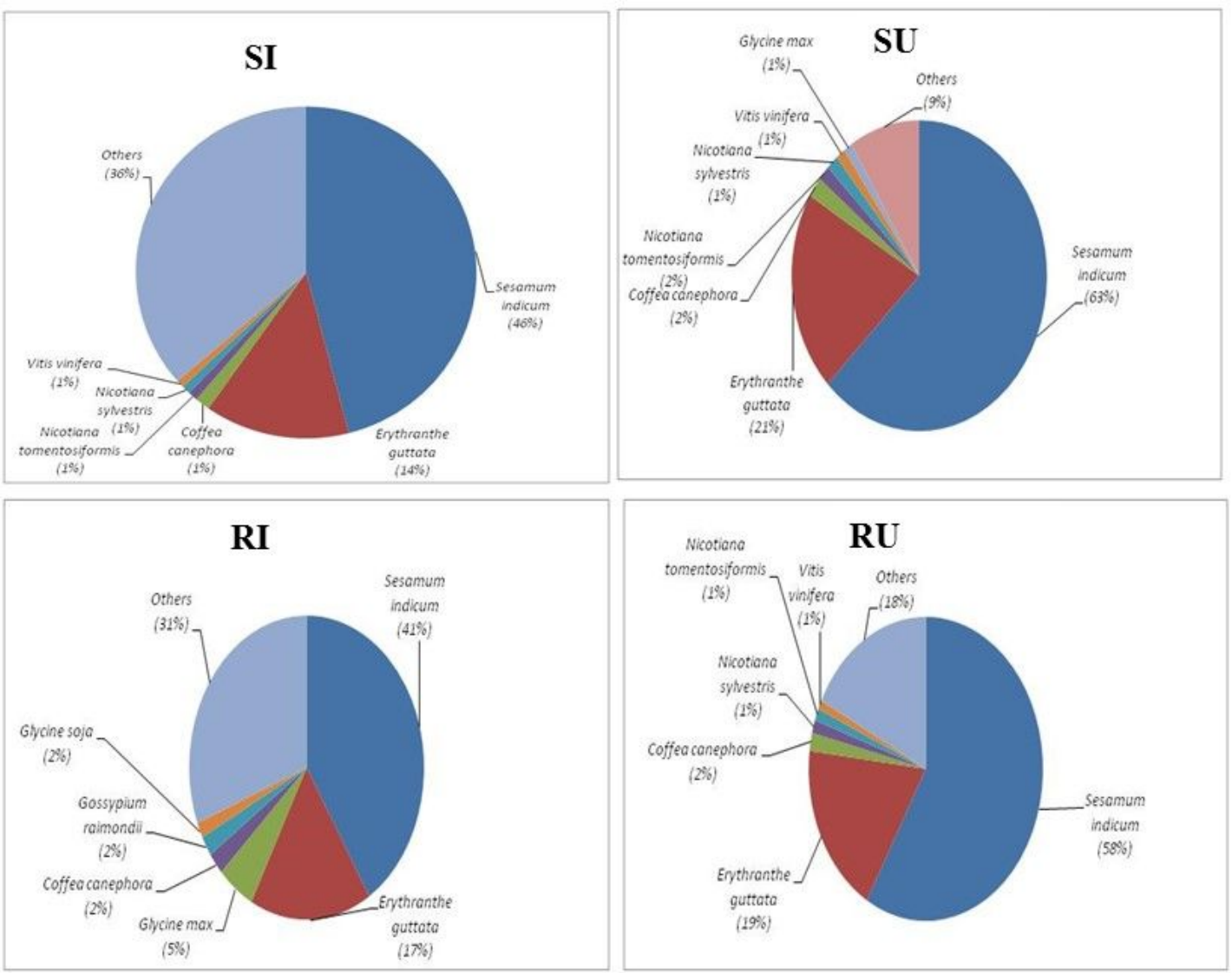

Figure 2

BLASTX top hit species distribution of CDS in the leaf transcriptome of Isabgol (Plantago ovata) 


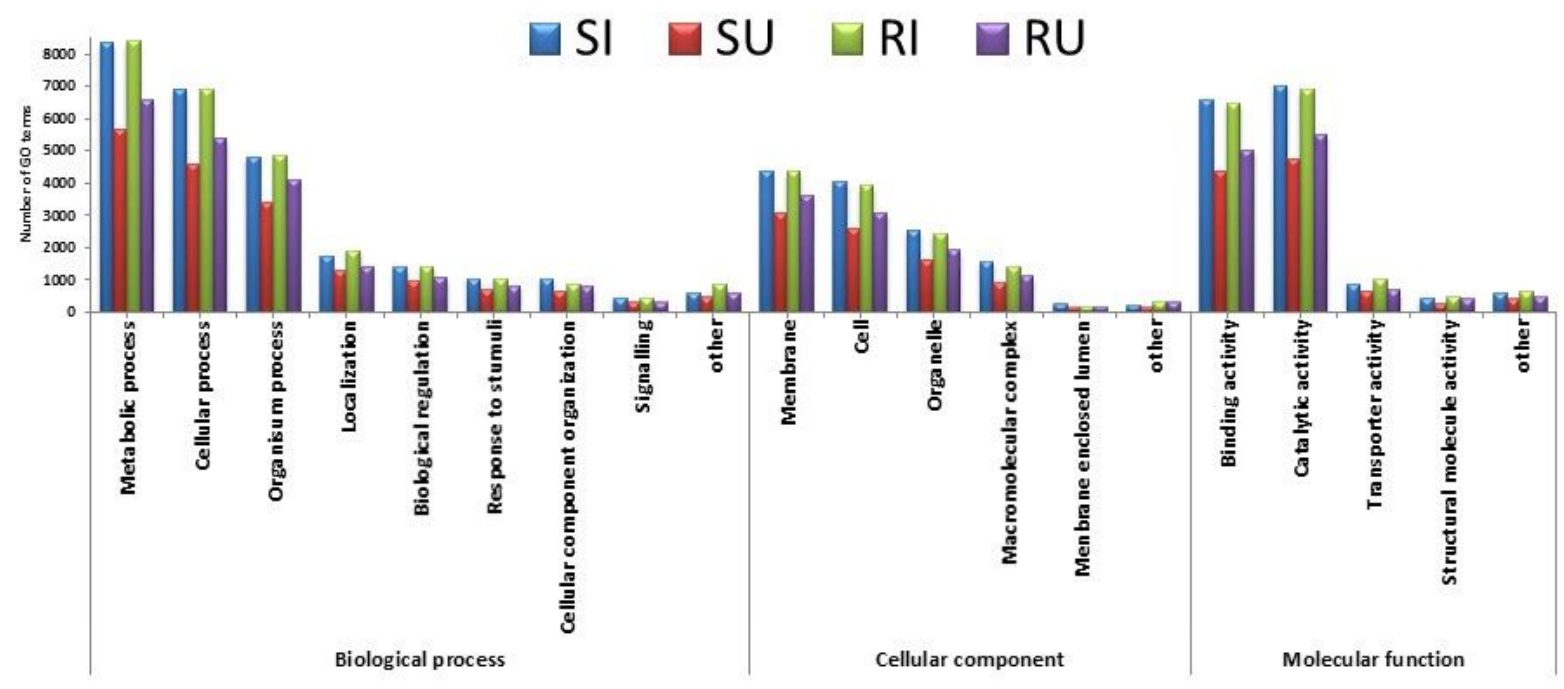

Figure 3

Distribution of GO term in the leaf transcriptome of Isabgol (Plantago ovata) 


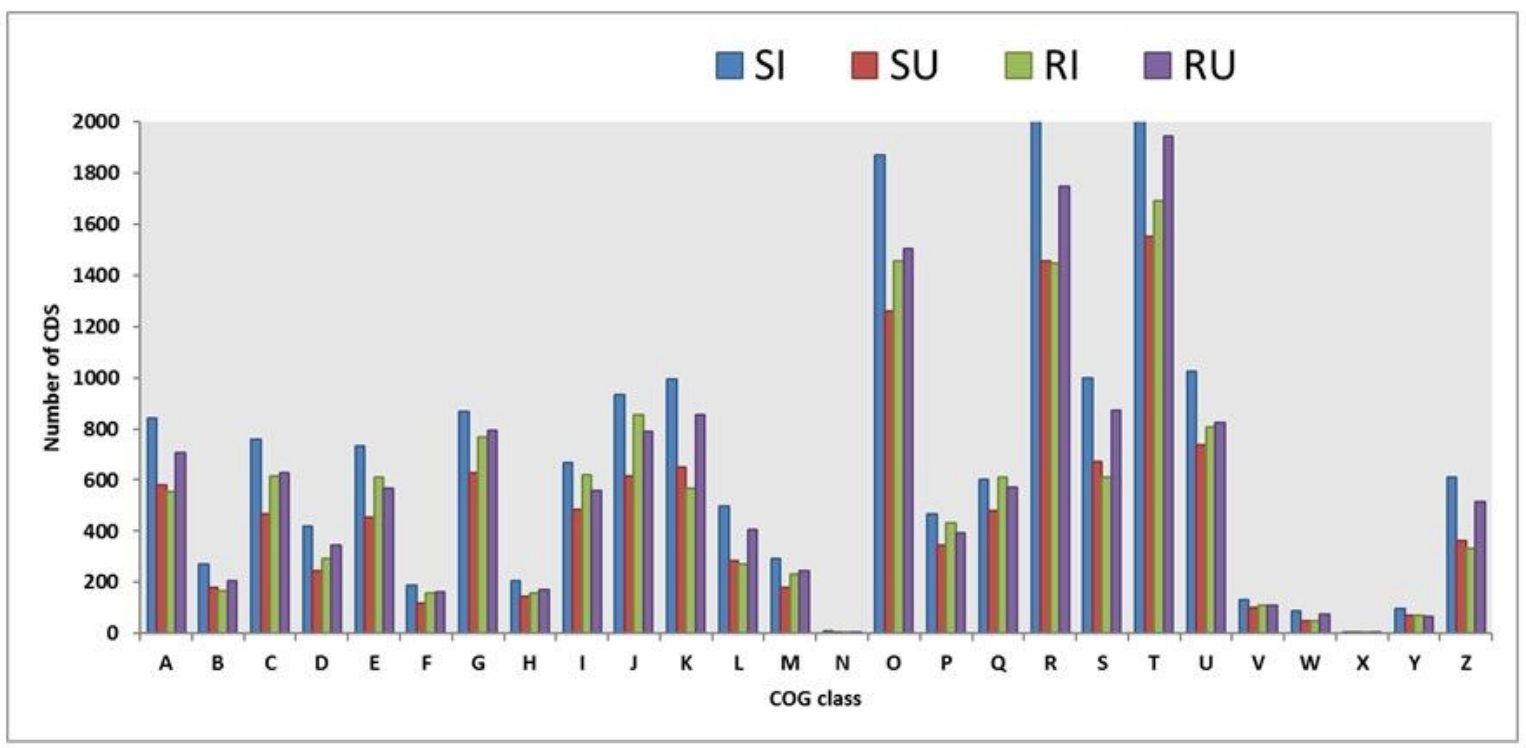

\section{Figure 4}

Clusters of orthologous groups (COG) functional classification of CDS in the transcriptome of Isabgol (Plantago ovata). A: RNA processing and modification, B: Chromatin structure and dynamics, C: Energy production and conversion, D: Cell cycle control, cell division, chromosome partitioning, E: Amino acid transport and metabolism, F: Nucleotide transport and metabolism, G: Carbohydrate transport and metabolism, H: Coenzyme transport and metabolism, l: Lipid transport and metabolism, J:Translation, ribosomal structure and biogenesis, K:Transcription, L: Replication, recombination and repair, M: Cell wall/membrane/envelope biogenesis, N: Cell motility, O: Posttranslational modification, protein turnover, chaperones, P: Inorganic ion transport and metabolism, Q: Secondary metabolites biosynthesis, transport and catabolism, R: General function prediction only, S: Function unknown, T: Signal transduction mechanisms, U: Intracellular trafficking, secretion, and vesicular transport, V: Defense mechanisms, W: Extracellular structures, X: multiple functions, Y: Nuclear structure and Z: Cytoskeleton. 

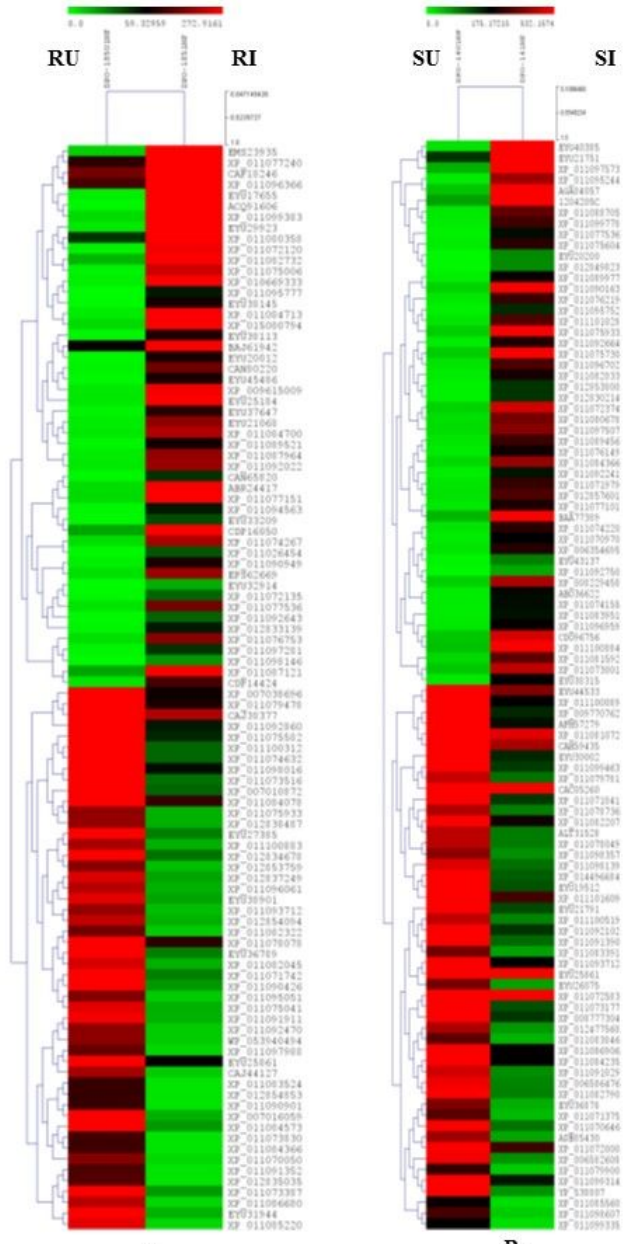

A.

B.

\section{Figure 5}

Heat map representing the top 50 up-regulated and top 50 down-regulated genes in the DM infected and control leaves of Isabgol (Plantago ovata). A) RU vs $\mathrm{RI}, \mathrm{B}) \mathrm{SU}$ vs SI 

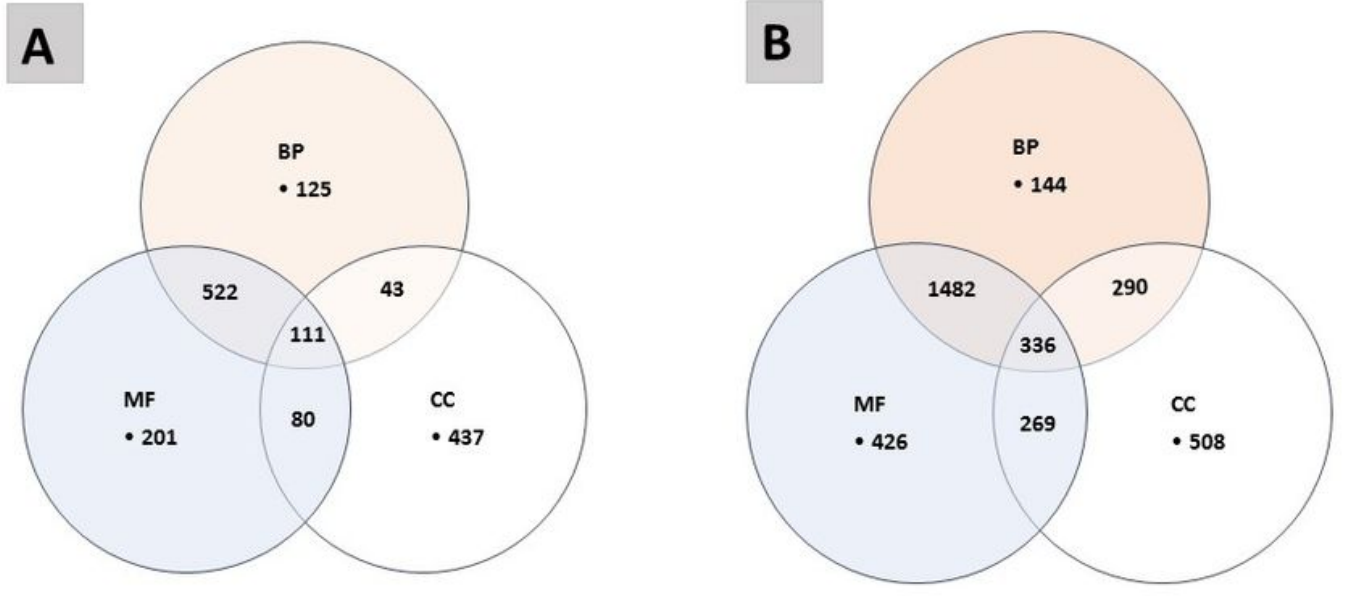

\section{Figure 6}

GO ontology of deferentially expressed genes in the leaf transcriptome of Isabgol (Plantago ovata). A) RU vs RI, B) SU vs SI. Molecular function (MF), Biological processes (BP) and Cellular component (CC)

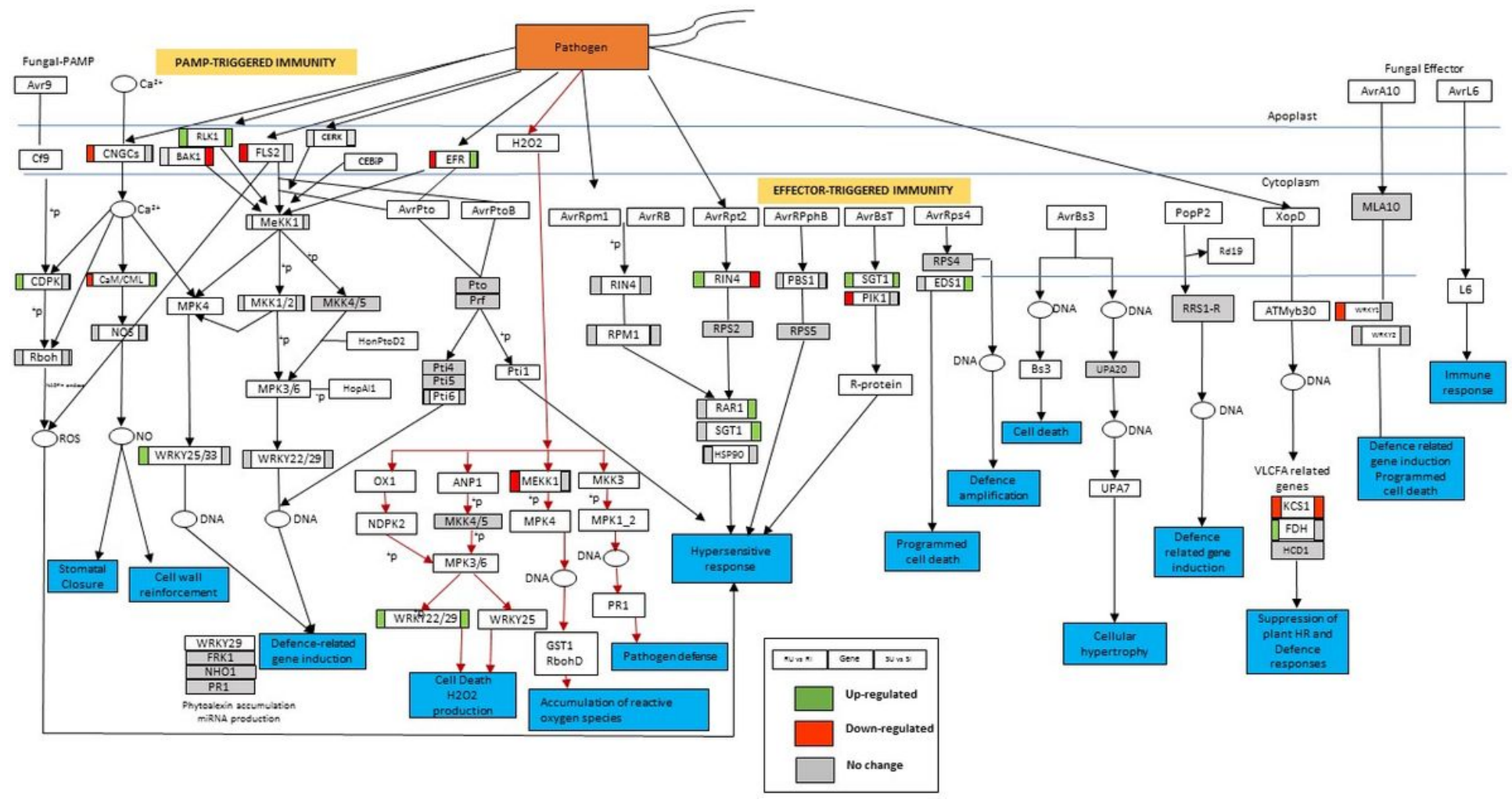

Figure 7 
Differentially expressed genes involved in plant pathogen interaction pathways: PAMP-triggered immunity (PTI) and Effector-triggered immunity (ETI) identified in DM infected and control pathways in Isabgol (Plantago ovata). Leucine-rich receptor-like protein kinase (FLS2), EF-TU RECEPTOR (EFR), BRI1associated receptor kinase (BAK1), Mitogen-activated protein kinase kinase kinase 1 (MEKK1), Mitogen-activated protein kinase kinase 2 (MKK1/2), Mitogenactivated protein kinase kinase 4/5 (MKK4/5), WRKY transcription factor 22 (WRKY29), WRKY transcription factor 25 (WRKY33), Cyclic nucleotide-gated ion channel (CNGC), Calcium-dependent protein kinase (CDPK), Calmodulin-binding transcription activator (CaM), Calcium-binding protein (CML), Respiratory burst oxidase homolog protein (RBOH), Nitric oxide synthase (NOS), G-type lectin S-receptor-like serine/threonine-protein kinase(RLK1), Chitin elicitor binding protein (CEBiP), Chitin elicitor receptor kinase 1 (CERK), FLG22-induced receptor-like kinase 1 (FRK1), Glycerol kinase (NHo1), Pathogenesis-related protein 1 (PR1), Serine-threonine kinase (Pto), Resistance gene (PRF), Pathogenesis-related genes transcriptional activator (PTI6), Pathogenesis-related genes transcriptional activator (PTI4), Pathogenesis-related genes transcriptional activator (PTI5), Disease resistance protein RPM1 (RIN4), Serine/threonine-protein kinase PBS1 (PBS1), Disease resistance protein RPM1(RPM1), Disease resistance protein RPS2 (RPS2), Cysteine and histidine-rich domain-containing protein RAR1 (RAR1), Protein SGT1 homolog (SGT1), Heat shock protein 90 (HSP90), Serine/threonine-protein kinase CDL1 (PIK1), Disease resistance protein RPS4 (RPS4), Protein EDS1 (EDS1), Transcription factorUPA20, Disease resistance protein RRS1-R (RRS1-R), Very-long-chain (3R)-3-hydroxyacyl-CoA dehydratase PASTICCINO 2 (HCD1), Intracellular mildew A 10 (MLA10), WRKY transcription factor 1, WRKY transcription factor 2, R-Protein L6, Indole-3-pyruvate monooxygenase YUCCA3 (Bs2), ATMYB30,3-ketoacyl-CoA synthase 1(KCS1), Formate dehydrogenase (FDH), Transcription factor UPA7 and Disease resistance protein RPS5.

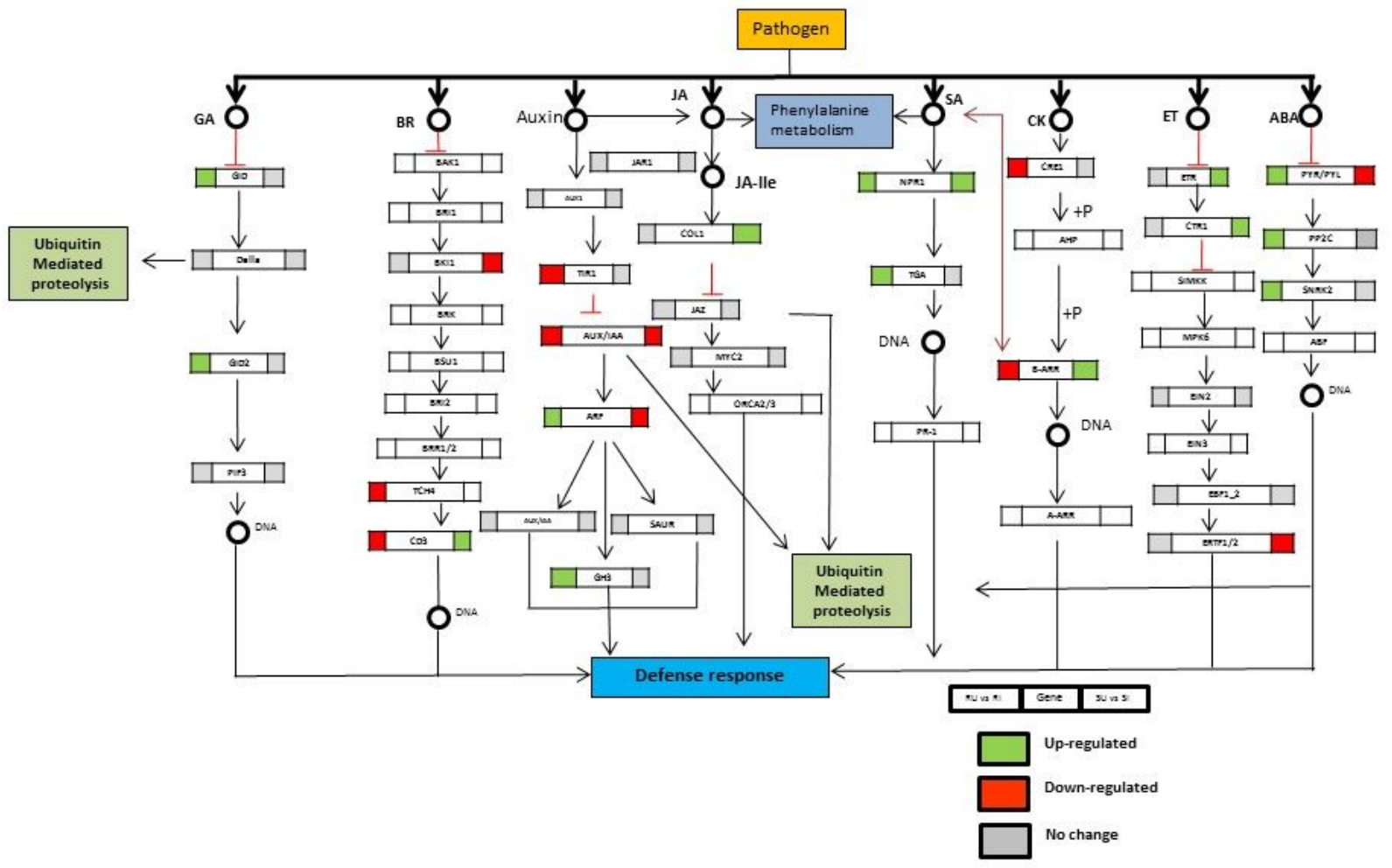

Figure 8

Differentially expressed genes (DEGs) involved in the phytohormone signaling pathways Identified in the leaf transcriptome of Isabgol (Plantago ovata); Abscisic acid receptor pyr/pyl family (PYR/PYL), Protein phosphatase 2c (PP2C), Serine/threonine-protein kinase srk2 (SNRK2), ABA responsive element binding factor (ABF), Ethylene receptor (ETS/ETR), Serine/threonine-protein kinase (CTR1), Mitogen-activated protein kinase kinase (SIMKK), Mitogen-activated protein kinase 6 (MAP6), Ethylene-insensitive protein 2 (EIN2), Ethylene-insensitive protein 3 (EIN3), Ein3-binding f-box protein (EBF1/2), Ethylene-responsive transcription factor 1/2 (ERTF1/2), Jasmonic acid-amino synthetase (JAR1), Coronatine-insensitive protein 1 (COI-1), Jasmonate ZIM domain-containing protein (JAZ), Transcription factor (MYC2), AP2-domain DNA-binding protein (ORCA2/3), Regulatory protein (NPR1), Transcription factor (TGA), Pathogenesisrelated protein 1 (PR-1), Brassinosteroid insensitive 1-associated receptor kinase 1 or leu-rich receptor serine/threonine protein kinase (BAK1), Protein brassinosteroid insensitive 1 (BRI1), BRI1 kinase inhibitor 1 (BKI1), BR-signaling kinase (BRK), Serine/threonine-protein phosphatase (BSU1), Protein brassinosteroid insensitive 2 (BRI2), Brassinosteroid resistant1/2 (BRR1/2), Xyloglucan:xyloglucosyl transferase (TCH4), Cyclin d3 (CD3), Gibberellin receptor (GID), Della protein (Della), F-box protein (GID2), Phytochrome-interacting factor 3 (PIF3), Auxin influx carrier (LAX3), Protein transport inhibitor response 1(TIR1), Auxin-responsive protein (ARP) (ARP), Auxin response factor (ARF), Auxin responsive gh3 gene family (GH3), Saur family protein (SAUR), Histidine 
kinase 3(CRE1), Histidine-containing phosphor transfer factor 5 (AHP5), Two-component response regulator ARR-B family (ARR-B) and Two-component response regulator ARR-A family (ARR-A).

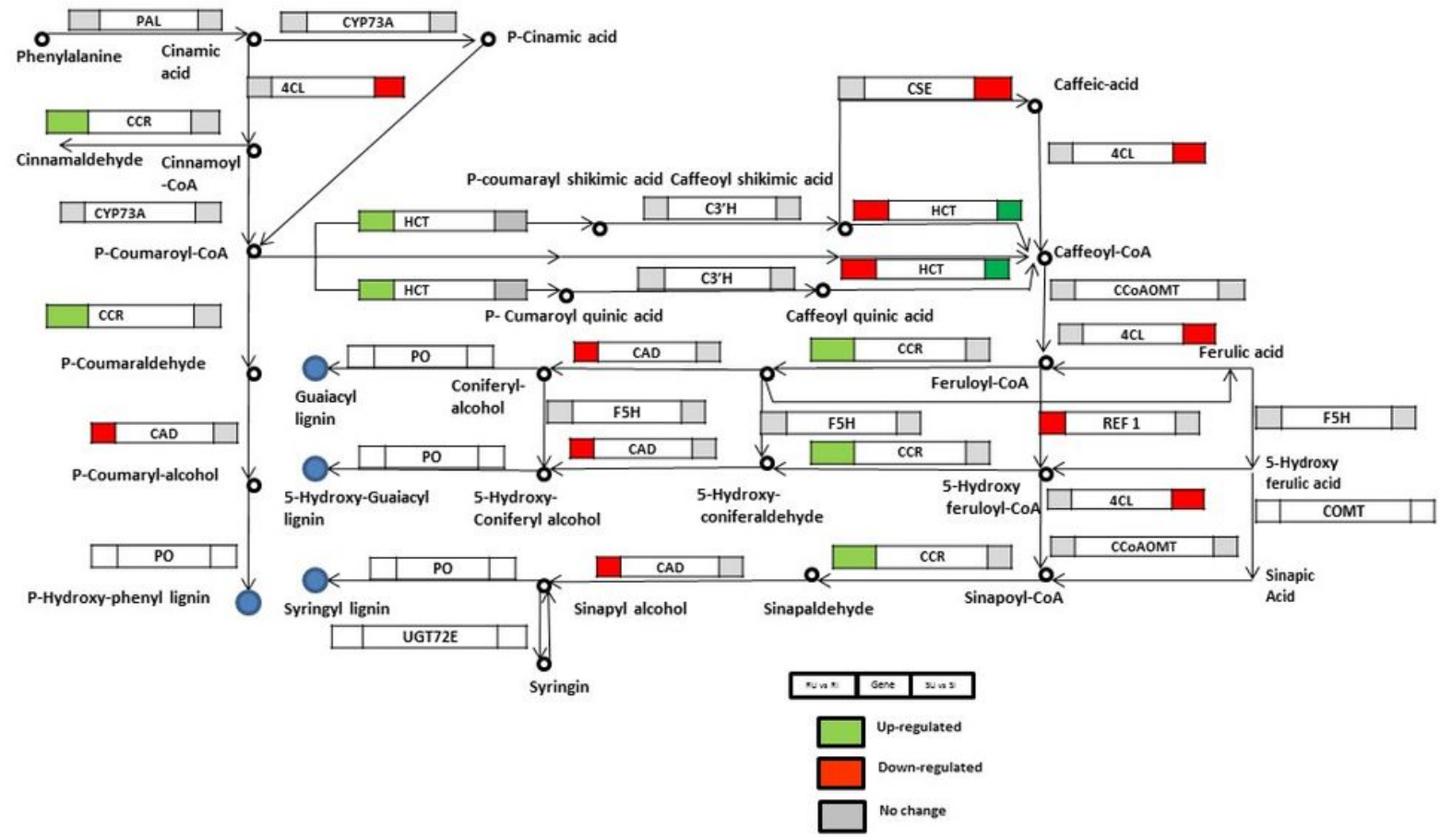

\section{Figure 9}

Differentially expressed genes (DEGs) involved in the phenylpropanoid biosynthetic pathway identified in the leaf transcriptome of Isabgol (Plantago ovata): Phenylalanine ammonia-lyase (PAL), Trans-cinnamate 4-monooxygenase (CYP73A), Cinnamoyl-CoA reductase (CCR), 4-Coumarate-CoA ligase (4CL), Cinnamyl-alcohol dehydrogenase (CAD), Catalase-peroxidase (PO), Shikimate O-hydroxycinnamoyltransferase (HCT), Coumaroylquinate (coumaroylshikimate) 3'-monooxygenase (CYP98A3/C3'H), Ferulate-5-hydroxylase (F5H), Caffeoylshikimate esterase (CSE), Caffeoyl-CoA 0methyltransferase (CCoAoMT), Coniferyl-aldehyde dehydrogenase (REF1), Coniferyl-alcohol glucosyltransferase (UGT72E) and Caffeic acid 3-0methyltransferase (COMT). 

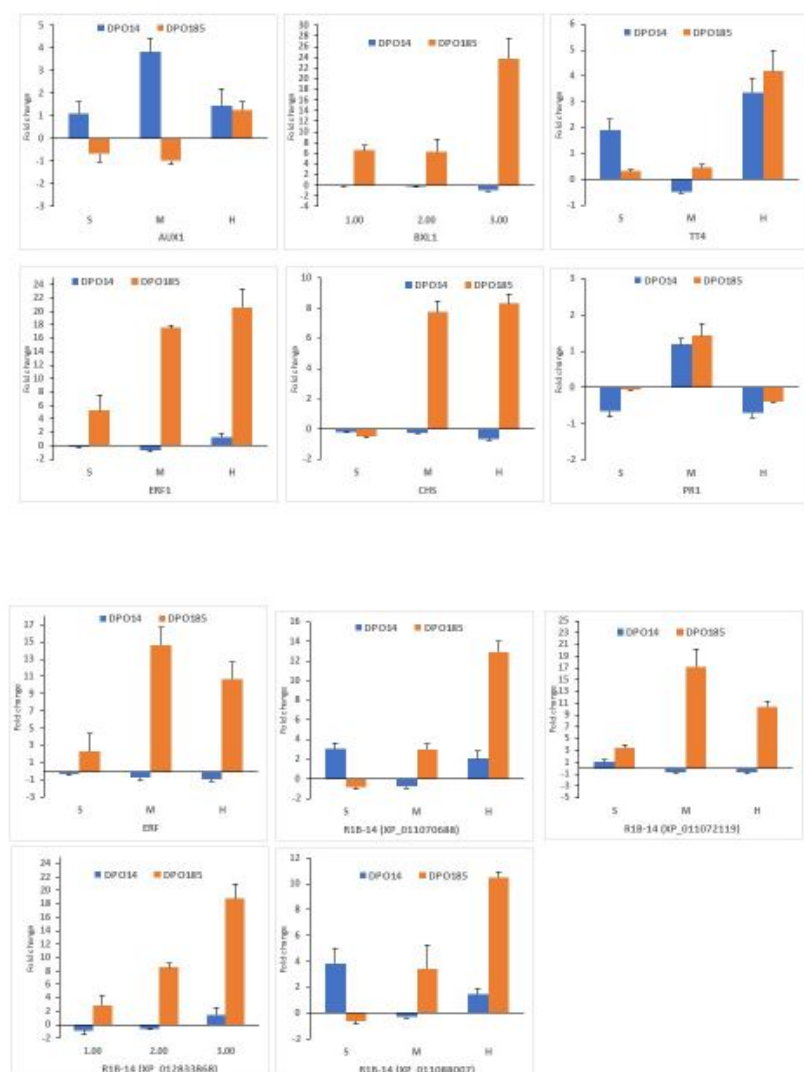

\section{Figure 10}

Validation of the differentially expressed transcripts by RT-qPCR. All data were normalized to the expression level of Ubiquitin gene. The data represents the change in the fold in the DM infected samples (S: slight, M:Medium and $\mathrm{H}$ : high infection levels) versus control samples (no DM infection). Where Auxin transporter protein 1 (AUX1), Beta-D-xylosidase 1 (BXL1), Chalcone and stilbene synthase (TT4), Ethylene response factor 1 (ERF1), Chalcone and stilbene synthase (CHS), Pathogen related protein 1 (PR1) Ethylene responsive factor (ERF) Late blight resistance protein homolog R1B-14 (XP_011070688), Late blight resistance protein homolog R1B-14 (XP_011072119), Late blight resistance protein homolog R1B-14 (XP_012833868), and Late blight resistance protein homolog R1B-14 (XP_011088007).

\section{Supplementary Files}

This is a list of supplementary files associated with this preprint. Click to download.

- AdditionalFiles.zip 